THIS MANUSCRIPT IS A PREPRINT AND HAS BEEN SUBMITTED FOR PUBLICATION IN WATER RESOURCES RESEARCH.

PLEASE NOTE THAT THE MANUSCRIPT IS CURRENTLY

UNDERGOING PEER REVIEW AND HAS YET TO BE FORMALLY ACCEPTED FOR PUBLICATION. SUBSEQUENT VERSIONS OF THIS MANUSCRIPT MAY HAVE SLIGHTLY DIFFERENT CONTENT. IF ACCEPTED, THE FINAL VERSION OF THIS MANUSCRIPT WILL BE AVAILABLE VIA THE 'Peer-reviewed Publication DOI' LINK ON THE RIGHT-HAND SIDE OF THIS WEBPAGE. PLEASE FEEL FREE TO CONTACT ANY OF THE AUTHORS; WE WELCOME FEEDBACK.

A PREPRINT 


\title{
Impact of Hydrostratigraphic Continuity in Heterogeneity on Brine-to-Freshwater Interface Dynamics; Implications from a 2-D Parametric Study in an Arid and Endorheic Basin
}

\author{
S.V. McKnight ${ }^{1 *}$, D.F. Boutt ${ }^{1}$, and L.A. Munk ${ }^{2}$ \\ ${ }^{1}$ Department of Geosciences, 627 North Pleasant Street, 233 Morrill Science Center, University of Massachusetts Amherst, \\ Amherst, Massachusetts 01003 \\ ${ }^{2}$ Department of Geological Sciences, 3211 Providence Drive, University of Alaska Anchorage, Anchorage, Alaska 99508
}

\section{Key Points:}

- Increased horizontal continuity of hydrostratigraphic units decreases the slope of brineto-freshwater interface geometry

- Increased horizontal hydrostratigraphic continuity increases time required to reach a new dynamic steady state following change in recharge

- Density-driven flow creates variable interface geometry and sensitivity in heterogeneous media that is not captured in homogeneous media

*Current address

Corresponding author: Sarah McKnight, smcknight@umass.edu 


\begin{abstract}
Despite the prevalence of density-driven flow systems in brine-rich aquifers of arid climates and coastal aquifers, the impact of realistic geologic conditions remains poorly constrained regarding interface geometry in arid regions and time-sensitive density-dependent dynamics in brine-bearing aquifers in general. Salar de Atacama provides an analog for exploring interface dynamics in arid regions. A site-specific 2D hydrostratigraphic interpretation is used to examine the dynamics of the brine-to-freshwater interface. With the same simulation framework and core data, a separate parametric series of hydraulic conductivity distributions with varying horizontal continuity provides a mechanistic explanation for observed dynamics. Comparing modeled interfaces and their sensitivity to perturbations in recharge in each realization yields insight into interface dynamics coupled with horizontal continuity in subsurface heterogeneity. Recharge fluctuation is introduced to each distribution following the interface reaching a dynamic steady state. Metrics for results evaluation include migration length, interface slope geometry, and response rate. Analyses suggest that the slope of the modeled interface shallows or decreases by 0.01 to $0.05 \mathrm{~m} \cdot \mathrm{m}^{-1}$ for every increase in continuity of highly permeable pathways by a factor. Increasing continuity also increases both the overall response times and the variability in response. Results indicate that accurate representations of transient dynamics in modeling density-driven brine-to-freshwater interface dynamics requires the consideration of heterogeneity, as saline intrusion in the highest continuity group extends over twice as far on average and the modeled interface takes over 43 percent more time on average to reach a new dynamic steady state when compared to their homogeneous counterparts.
\end{abstract}

\title{
Plain Language Summary
}

Differences in the density of groundwater from dissolved salt causes impacts groundwater flow which behaves differently under different subsurface conditions. This paper focuses on how spatial differences in porosity affects flow behavior and changes the risk of saline groundwater intrusion. Core and groundwater data from the southeastern edge of the salt flat in Salar de Atacama provides information on subsurface physical characteristics and groundwater chemistry. This data is used to create an interpretation of how flow properties vary in time and space. This provides a means for assessing the role of spatially variable geologic units on the geometry and the sensitivity of the brine-to-freshwater interface to changes in recharge to an aquifer. We use distributions of the area's geology to test different amounts of geologic variability in the horizontal versus the vertical direction. Results indicate that more horizontal continuity shallows the geometry and increases the the time required for a brine-to-freshwater interface to reach a new position following a change in recharge. These model results suggest that it is important to consider how differences in subsurface porosity impact the response time and the extent of saline intrusion for deserts as well as any other areas that might have salty groundwater.

\section{Introduction}

Numerical simulations of density-dependent flow assess the risk of saline groundwater intrusion in coastal areas (Meng et al., 2002; Trabelsi et al., 2013; J. W. Heiss \& Michael, 2014), and in arid and often endorheic basins where evaporation outpaces recharge and concentrates solutes in groundwater (Stein et al., 2019). The discrepancy in fluid density encourages the development of an interface where the denser brine underlies the less dense fluid to create a freshwater lens, which is commonly known as a brine-to-freshwater interface (Duffy \& Hassan, 1988; Philip \& van Duijn, 1996; Fan et al., 1996; Wooding et al., 1997; Houston et al., 2011). For interfaces located in arid and endorheic basins, the processes that control the geometry and sensitivity of such interfaces remain unconstrained (Tejeda et al., 2003; Vásquez et al., 2013). The global decline of groundwater storage in aquifers in endorheic basins (Wang et al., 2018) increases the need to refine density-dependent dynamics when coupled with perturbations in recharge in such environments (Condon \& Maxwell, 2019). 

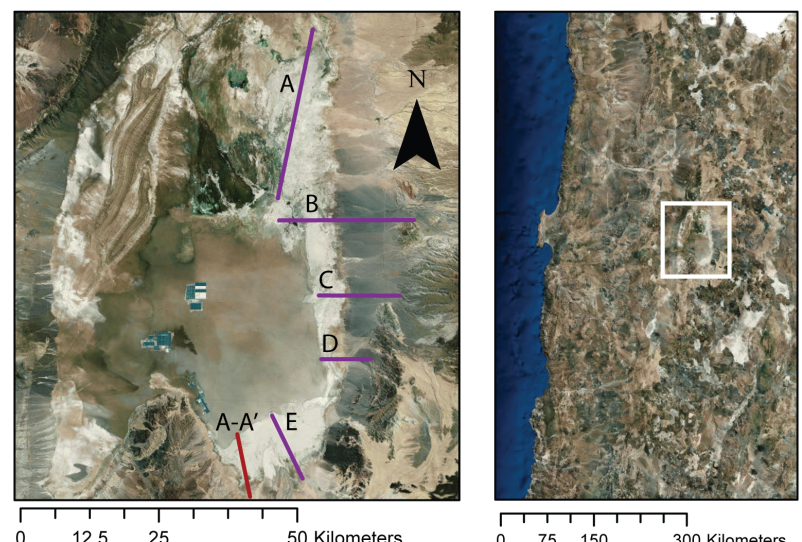

$\begin{array}{llllll}75 & 150 & & & \end{array}$

300 Kilometers
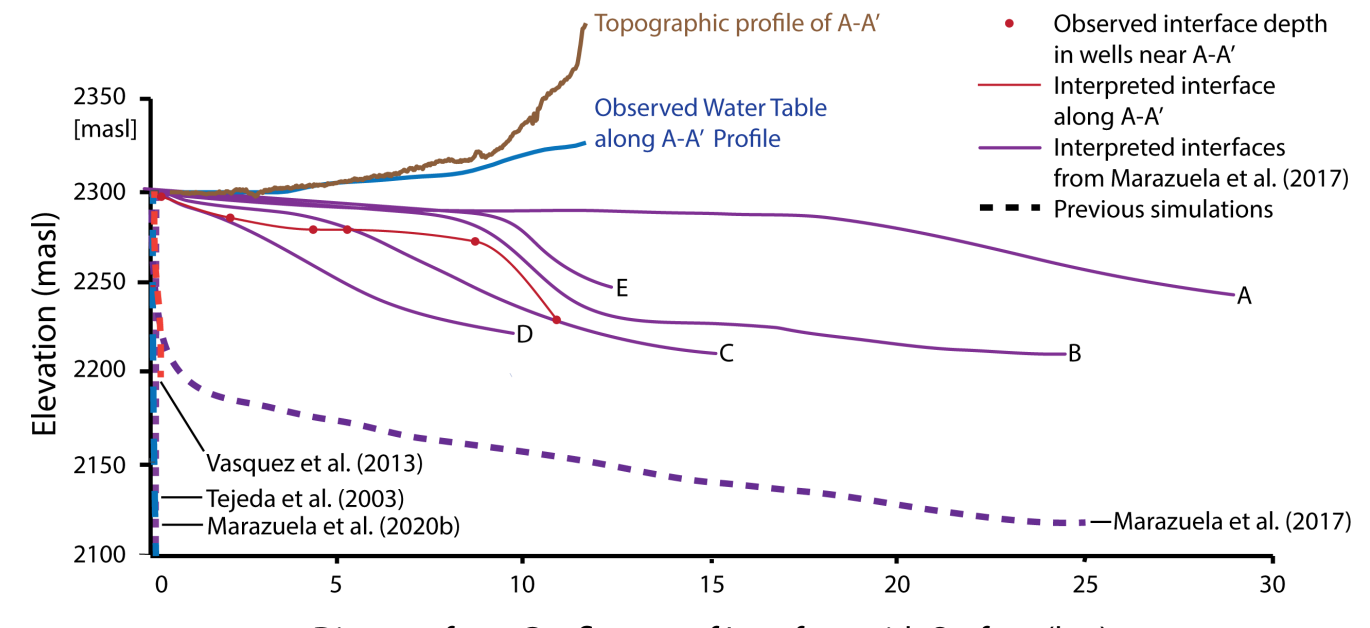

Distance from Confluence of Interface with Surface ( $\mathrm{km}$ )

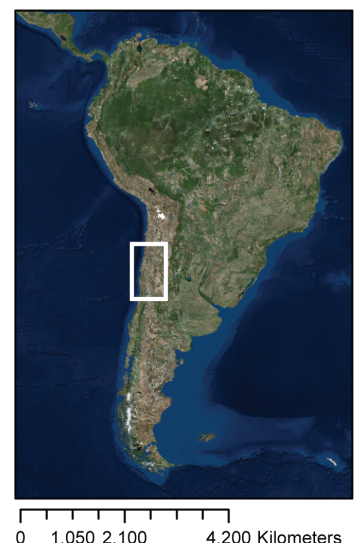

- $\quad$ Observed interface depth in wells near A-A'

- Interpreted interface along $A-A^{\prime}$

Interpreted interfaces from Marazuela et al. (2017)

Figure 1. Comparison of observed 2-D interface locations with numerical simulations (dashed lines) of the interface along the transitions zone of SdA. Observed interfaces A-E (purple solid lines) from Marazuela et al. (2017) with locations along the eastern margin of the salar, as seen in the reference map in the upper left corner. The observed interface for this study along the A-A' transect is the solid red line.

The Ghyben-Herzberg approximation (Morgan et al., 2012) serves as a simple analytical solution to approximate the geometry of the brine-to-freshwater interface (Post et al., 2018), but it cannot account for time-dependent dynamics of density-dependent flow. Numerical simulations represent a tool for time-dependent analysis of saline intrusion, but simulations of saturated subsurface density-dependent fluid flow in homogeneous porous media do not ubiquitously capture the interface's geometry under realistic hydraulic conditions due to influences from heterogeneity (Post et al., 2007). Density-dependent numerical simulations of brine-tofreshwater interfaces in arid basins have either been homogeneous (Vásquez et al., 2013; Tejeda et al., 2003) or simply layered models of local geology that underestimate basin-scale heterogeneity and produce unrealistic results of the modeled interface (Marazuela et al., 2018). Previous geostatistical modeling documented the influence of subsurface heterogeneity on seawater circulation in coastal aquifers (Michael et al., 2016; Geng et al., 2020; Kreyns et al., 2020). However, the extent to which the continuity of subsurface heterogeneity impacts time-sensitive dynamics in general and the interface geometry for aquifers in arid basins specifically remains unconstrained. 
This paper documents that heterogeneity influences both the steady-state geometry of the brine-to-freshwater interface and the time-sensitive reaction of the interface in response to perturbations in recharge. Salar de Atacama provides an ideal site for assessing the role of heterogeneity because of its complex structural history (Reutter et al., 2006) and extensive development of evaporite sequences (Jordan et al., 2004). The interface between brine and laterally inflowing freshwater has a shallow geometry that has not been captured by previous modeling of density-driven flow in the basin (Figure 1). A geostatistical approach with equally probable distributions of hydraulic conductivity $(\mathrm{K})$ based on field data from SdA provides a means for investigating the role of continuity in heterogeneous geology on density-driven dynamics. This represents the first attempt to constrain the impact of subsurface heterogeneity on brineto-freshwater interface geometry for arid and endorheic basins specifically. Our findings are also the first definition of time-sensitive response of saline intrusion to perturbations in recharge in relation to variations in continuity.

\section{Background}

\subsection{Hydrogeologic setting of salars}

Salars ("salt flats") comprise brine-bearing aquifers with subsurface heterogeneity in porous media and distinct hydrologic dynamics. Salars primarily consist of evaporites in basins with an annually negative hydrologic budget on average (Rosen, 1994; Tyler et al., 2006; HernándezLópez et al., 2014). Endorheic basins provide an ideal environment for evaporite accumulation due to their tendency to inhibit the effective discharge of incoming sources (Eugster, 1980; Houston et al., 2011), but salars also occur in open basins with a negative water budget (Rosen, 1994). Brine that is more saline than seawater ( $>35 \mathrm{ppt}$ ) can occur, and the higher discrepancy in density results in a relatively shallower slope in the interface between the brine and freshwater (Yechieli, 2000). Salars can develop a range of stratigraphically complex aquifers because their climate-sensitive change in areal extent can create a series of interbedded lithologies (Houston, 2009), as specifically documented in Munk et al. (in review). Since brine-bearing aquifers commonly exist in tectonically active endorheic basins (Yager et al., 2017), faulting among lithologies further complicate the lateral continuity of subsurface heterogeneity and produce interface geometries that defy theory when intersecting fault systems (Yechieli, 2000). This study therefore provides a sensitivity analysis for investigating the role of heterogeneity in density-dependent dynamics of such aquifers.

Aquifers in these environments also exhibit recharge-controlled water table configurations (Haitjema \& Mitchell-Bruker, 2005). The resulting lateral inflow dominates long-term recharge as predicted by the Toth flow model (Rissman et al., 2015; Qureshi, 2011; Carmona et al., 2000), which can include groundwater flow into a topographically separate and relatively upgradient basin (Maxey, 1968; Schaller \& Fan, 2009; Montgomery et al., 2003). Therefore, while surface recharge provides a mechanism for sustaining groundwater levels (Boutt et al., 2016) and solute delivery (Munk et al., 2018), lateral subsurface inflow represents the longterm recharge mechanism (Scanlon et al., 2006; Houston, 2009; Ye et al., 2016). Basin-scale recharge trends in arid climates can change over relatively short (i.e. interdecadal and millennial) timescales (Placzek et al., 2009), highlighting the importance of considering climate-driven shifts even if short-term hydrology appears to be stable (Zhu et al., 1998). To date, there has been no study that has characterized the impact of heterogeneity on the time-sensitive response of brine-to-freshwater interfaces to perturbations in subsurface lateral inflow (Sanford \& Pope, 2010; Ferguson \& Gleeson, 2012). The framework for the numerical simulations include subsurface lateral inflow as the main source of recharge and evaporation at the margin of the modeled salar as the primary source of discharge.

\subsection{Sensitivity analyses on density-driven flow systems}

Many studies have documented and simulated density-dependent flow and its resulting brine-to-freshwater interface in both coastal (Yechieli, 2000; Werner \& Simmons, 2009; Tra- 
belsi et al., 2013) and inland aquifers (Fan et al., 1996; Wooding et al., 1997; Tejeda et al., 2003). Studies that numerically assess the factors that impact saline intrusion commonly examine a single influence on the interface's dynamics, such as changes in recharge (Post et al., 2019) or discharge (Werner \& Simmons, 2009). For coastal aquifers, studies primarily focus on coupling density-dependent flow with solute transport in order to define the risk of saline groundwater intrusion to inland groundwater resources (Meng et al., 2002; Werner \& Simmons, 2009; Morgan et al., 2012). Such studies frequently investigate the sensitivity of brine-to-freshwater interface migration via solute transport coupled with various influences, including but not limited to the buoyancy effect from density-depedent flow (Bear, 1972; Werner et al., 2013), waveinduced groundwater circulation cells (J. Heiss et al., 2017), fluctuating circulation from tidal forcing (J. W. Heiss \& Michael, 2014; Bailey, 2015), variations in circulation cell size from bedform topography (Konikow et al., 2013), increased landward interface migration from sea level rise (Yechieli et al., 2010; Ketabchi et al., 2016), increased supratidal salinity from evaporation (Geng \& Boufadel, 2015), increased interface migraton via preferential pathways from conducive faulting (Trabelsi et al., 2013), anthropogenic pumping of inland fresh groundwater (Ferguson \& Gleeson, 2012), and heterogeneity in geologic media (Michael et al., 2016; Michael \& Khan, 2016; Liu et al., 2014; Mahmoodzadeh \& Karamouz, 2019). While studies of saline groundwater intrusion primarily focus on coastal environments, inland and arid basins are also prevalent sites of brine development (Rissman et al., 2015) and comprise evaporitedominated geology and arid geomorphology that is unique from coastal environments and yet remains uncomprehensively modeled on a global scale (Houston et al., 2011). Specifically for inland and arid basins, studies of density-dependent flow primarily utilize analytical methods or numerical simulations to document groundwater circulation within steady state conditions without considering either variations in steady-state conditions or transient responses to perturbations in recharge (Duffy \& Hassan, 1988; Fan et al., 1996; Wooding et al., 1997; Hamann et al., 2015).

\subsection{Numerical simulations of density driven flow \& heterogeneity}

Since geologically heterogeneous media comprise the majority of aquifers (Gelhar et al., 1992), many numerical studies have investigated the impact of subsurface heterogeneity on densitydependent flow dynamics in order to elucidate more realistic mechanistic explanations for the documented salinity distributions and transport flowpaths (Schincariol et al., 1997), especially for coastal aquifers (Russoniello et al., 2013). Among them, Sawyer et al. (2014) establish that hydraulically conducive stratigraphic features can control geochemical fluxes in near-shore aquifers. Michael et al. (2016) provide an extensive analysis on the impact of geologic heterogeneity on seawater circulation, while Kreyns et al. (2020) document that freshwater discharge can extend further offshore in heterogeneous volcanic aquifers when compared to homogeneous counterparts. (Geng et al., 2020) use simulations to investigate the impact of subsurface heterogeneity on tidally-influenced circulation, thereby confirming the importance of coupling heterogeneity with influences on an aquifer's hydrologic dynamics in order to further constrain geologic impacts on solute transport. Michael and Khan (2016) further detail heterogeneity's influence on variable solute transport and decreased travel time through an aquifer in response to relatively deeper groundwater pumping. While freshwater aquifer storage in coastal aquifers may experience a multi-decadal time lag response due to changes in recharge resulting from fluctuations in brine-to-freshwater interface migration (Klammler et al., 2020), the impact of continuity in heterogeneity on further increasing such a time lag but remains unconstrained. This study therefore aims to further define how continuity in basin-scale heterogeneity impacts the time sensitivity of density-dependent response to perturbations in recharge.

Given the resource-rich importance (Kunasz, 1980; Munk et al., 2016) and prevalence of brine-bearing aquifers underlying inland and arid basins (Yechieli \& Wood, 2002; Wang et al., 2018), simulating density-dependent flow in these systems has increased in recent years. These basins' unique hydrologic conditions, such as lack of tidal influence and distinct evaporation patterns (Hernández-López et al., 2014), further elevate the need for environment-specific modeling. Simulations of density-dependent dynamics in arid, inland basins commonly model 
either homogeneous conditions (Tejeda et al., 2003) or simple stratigraphic interpretations with continuous, single-layer aquitards (Duffy \& Hassan, 1988; Marazuela et al., 2018). While Marazuela et al. (2018) document the shallowing of the interface which presumably results from an underlying lower-K confining unit, the resulting modeled interface does not capture realistic geometry (Figure 1). While continuity in stratigraphic units' hydraulic conductivity increases saline groundwater circulation (Michael \& Khan, 2016), the degree to which basin-scale hydrostratigraphic complexity influences salinity distributions and thus brine-to-freshwater interface geometry remains unclear for arid basins (Houston et al., 2011). The series of numerical simulations presented here represent the first attempt to characterize the impact of heterogeneity on brine-to-freshwater interface geometry for arid and inland basins specifically, as well as provide insight on the impact of heterogeneity on density-dependent dynamics to changes in recharge for brine-bearing aquifers in general. This work is highly important because of the need to understand the interplay of freshwater and underlying saline water as these basins have continued pressures put on freshwater and resource extraction.

\section{Simulations}

Saturated density-dependent groundwater flow was simulated using SEAWAT, a cell-centered finite difference approximation that solves both saturated fluid flow and solute transport (Langevin $\&$ Guo, 2006). To address the role of heterogeneity on brine-to-freshwater interface sensitivity, we use a geostatistical approach with a series of realizations of $\mathrm{K}$ fields by kriging available hydrogeologic data for SdA with a Markov approach using T-PROGS software (Carle, 1999). We base the transition probabilities for the $\mathrm{K}$ distributions on the lithologies documented from diamond drill cores recovered from the southeastern margin of SdA (S1). To address the sitespecific implications for SdA, a separate hydrostratigraphic framework (HSF) was developed for the A-A' transect noted in Figure 1 where brine underlying the salar interacts with shallow subsurface laterally inflowing freshwater to create a brine-to-freshwater interface along the southeastern margin (Figure S2). The HSF relies on a geologic model that was developed from core and well data, geophysical surveys, and knowledge of surface geology and basin structure based on previous literature (Jordan et al., 2002; Lowenstein et al., 2003; Mpodozis et al., 2005; Reutter et al., 2006), as further described in the supplementary section (S1) as well as filed observations by the authors.

\subsection{Boundary \& initial conditions}

The finite grid and boundary conditions for the simulations are based on representations of aquifer characteristics for the modeled basin, including recharge via subsurface lateral inflow, discharge via ET, and topography based on the A-A' transect (Figure 1). Excepting changes in recharge and the $\mathrm{K}$ distributions, all other physical boundary and initial conditions remain constant. Figure 3 illustrates initial and boundary conditions. The domain is $13,000 \mathrm{~m}$ long by $300 \mathrm{~m}$ deep, and is discretized into $100 \mathrm{~m}$ long by $10 \mathrm{~m}$ deep grid cells. The framework represents one side of a basin because the hypothetical symmetry of a basin renders the simulation of both sides redundant and therefore unnecessary. The surface boundary is based on smoothed elevation models of the topography at SdA from the available 10 meter-resolution digital elevation data. A Dirichlet boundary represents specified head for the modeled edge of the nucleus, which is approximately $1 \mathrm{~m}$ below the modeled nucleus surface. The entire left side of the model domain that represents the edge of the nucleus has a constant dissolved salt concentration of $0.2 \mathrm{~g} \cdot \mathrm{cm}^{-3}$ which represents the maximum concentration observed in highly saline brines. A Neumann boundary condition represents the modeled subsurface laterally inflowing flux of freshwater on the right side of the model domain has no concentration of dissolved salt. Discharge is represented as evaporation via a head-dependent flux that equates to an equivalent flux of the baseline inflow flux of $500 \mathrm{~m}^{-3} \cdot \mathrm{d}^{-1}$ if the hydraulic head is less than 1 meter from the modeled surface (Figure 3). All other boundaries not otherwise described have no flux in either fluid or solute. The initial solute concentration for the entire extent of the domain is $0 \mathrm{~g} \cdot \mathrm{cm}^{-3}$. Initial hydraulic head is a uniform $1 \mathrm{~m}$ below the modeled surface. 


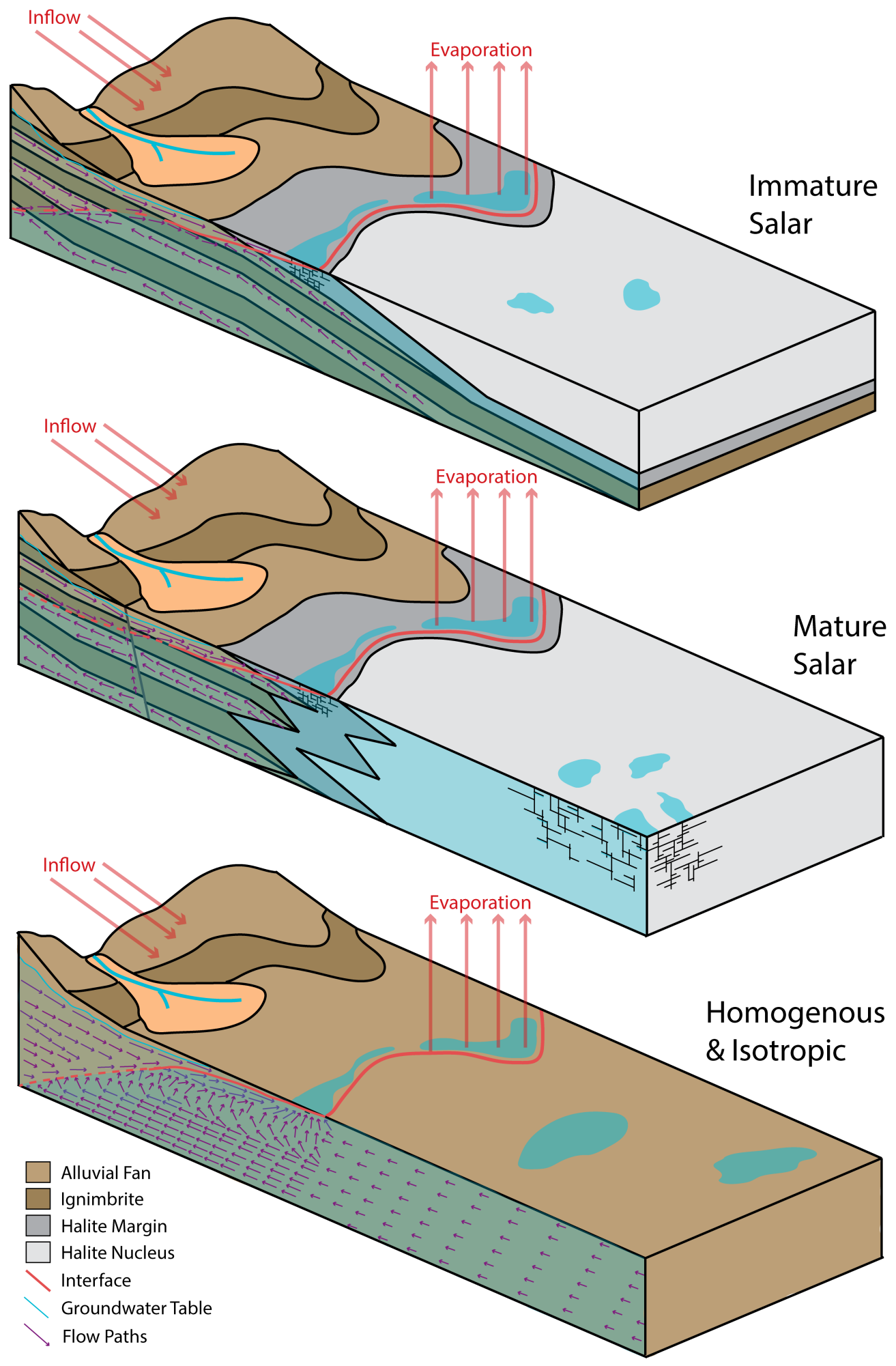

Figure 2. Conceptual illustration of mature versus immature salars and their homogeneous counterpart, with the resulting brine-to-freshwater interface and flow vectors. Adapted from Houston et al. (2011). 


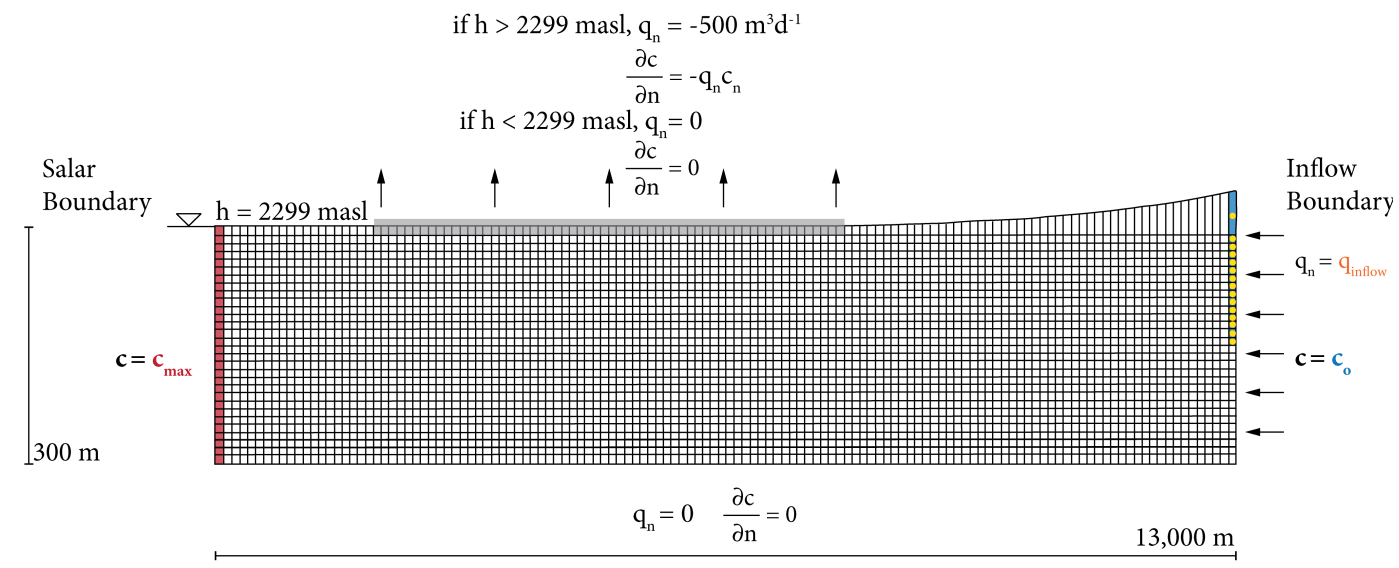

Figure 3. Boundary conditions for the $300 \mathrm{~m}$ deep by 13,000 $\mathrm{m}$ long 2-D model framework with a vertical exaggeration of 10 . Note that the model is discretized into 30 by 130 cells each cell having the dimensions of $10 \mathrm{~m}$ deep by $100 \mathrm{~m}$ wide. Also note that $\mathrm{c}_{\max }=0.2 \mathrm{~g} \cdot \mathrm{cm}^{-3}, \mathrm{c}_{\mathrm{o}}=0 \mathrm{~g} \cdot \mathrm{cm}^{-3}$, and that $\mathrm{q}_{\text {inflow }}$ varies by 300,500 , and $700 \mathrm{~m}^{3} \cdot \mathrm{d}^{-1}$. Vertical exaggeration is 10 .

\begin{tabular}{lll}
\hline Parameter & Value & Unit \\
\hline Domain length & 13,000 & $\mathrm{~m}$ \\
Domain thickness $(\mathrm{B})$ & 300 & $\mathrm{~m}$ \\
Longitudinal dispersivity $\left(\alpha_{\mathrm{L}}\right)$ & 10 & $\mathrm{~m}$ \\
Horizontal transverse dispersivity $\left(\alpha_{\mathrm{H}}\right)$ & 1 & $\mathrm{~m}$ \\
Vertical transverse dispersivity $\left(\alpha_{\mathrm{V}}\right)$ & 0.01 & $\mathrm{~m}$ \\
Diffusion coefficient & $1 \cdot 10^{-6}$ & $\mathrm{~m} \cdot \mathrm{s}^{-1}$ \\
Effective porosity $(\vartheta)$ & 0.3 & - \\
Constant head at nucleus boundary & 2299 & $\mathrm{masl}$ \\
Freshwater density $\left(\rho_{\mathrm{o}}\right)$ & 1 & $\mathrm{~g} \cdot \mathrm{cm}^{-3}$ \\
Brine density $\left(\rho_{\text {max }}\right)$ & 1.2 & $\mathrm{~g} \cdot \mathrm{cm}^{-3}$ \\
Storativity $\left(\mathrm{S}_{\mathrm{s}}\right)$ & $1 \cdot 10^{-4}$ & $\mathrm{~m}{ }^{-1}$ \\
Specific yield $\left(\mathrm{S}_{\mathrm{y}}\right)$ & 0.02 & - \\
Vertical anisotropy $(\mathrm{Kh} / \mathrm{Kv})$ & 10 & -
\end{tabular}

Table 1. Constant boundary conditions for the numerical modeling approach. These conditions are constant throughout the modeled time for every model. Note that the listed vertical anisotropy value applies for the non-isotropic models.

Values of longitudinal, horizontal transverse, and vertical transverse dispersivity in all models are $10 \mathrm{~m}, 1 \mathrm{~m}$, and $0.01 \mathrm{~m}$ respectively. These values are consistent with modeling aquifers of this scale (Gelhar et al., 1992). All iterations run with the above-described initial conditions to $3 \cdot 10^{6}$ days. The models then run for another $3 \cdot 10^{6}$ days following a perturbation in hydrologic conditions in order to assess the sensitivity of the brine-to-freshwater interface. Table 1 lists the constant boundary conditions for the numerical simulation.

\subsection{Simulating perturbations in recharge}

Groundwater inflow is the only boundary condition in this study that experiences variation for every realization of $\mathrm{K}$. The simulations were run to an initial steady state with no interface movement in order to establish an interface geometry from initial conditions. Each re- 
alization is subsequently exposed to three different recharge scenarios as step functions: an increase in recharge $\left(700 \mathrm{~m}^{3} \cdot \mathrm{d}^{-1}\right)$, an equal decrease in recharge $\left(300 \mathrm{~m}^{3} \cdot \mathrm{d}^{-1}\right)$, and no perturbation in recharge $\left(500 \mathrm{~m}^{3} \cdot \mathrm{d}^{-1}\right)$. The development of the boundary condition representing recharge is based on the assumption that arid hydrology relies on interbasin flow that is characterized by long residence times and therefore prolonged variations in recharge, as supported by sitespecific data (Houston, 2009; Ortiz et al., 2014; Corenthal et al., 2016). While previous numerical studies have included direct recharge (Marazuela et al., 2018), the impact of direct recharge is not considered in this study because arid basins exhibit minimal to no surficial recharge where ET outpaces precipitation rates (Scanlon et al., 2006) and the dominant recharge mechanism of such basins is lateral groundwater flow following the Toth model (Schaller \& Fan, 2009).

\subsection{Distributions of hydraulic conductivity}

Geostatistic realizations of heterogeneous distributions were based on $\mathrm{K}$ values assigned to lithostratigraphic units from the study site in the southeastern margin of SdA. The hydraulic conductivity values are based on correlating geologic and hydraulic data from the 29 cores (Table S1) and 48 wells (Table S2) from within the approximately $130 \mathrm{~km}^{2}$ area that comprises the southeastern margin of SdA. The hydrostratigraphic correlation is based on over 50 hydraulic tests that have occurred in the area. Hydrostratigraphic interpretations were separated into five lithologic facies based on the conceptualization in Munk et al. (in review): mediumgrain clastic from alluvial fan deposits $\left(10 \mathrm{~m} \cdot \mathrm{d}^{-1}\right)$, fine-grain carbonate $\left(1 \mathrm{~m} \cdot \mathrm{d}^{-1}\right)$, vuggy carbonate $\left(100 \mathrm{~m} \cdot \mathrm{d}^{-1}\right)$, un-fractured ignimbrite $\left(0.01 \mathrm{~m} \cdot \mathrm{d}^{-1}\right)$, and interbedded gypsum and carbonate $\left(0.1 \mathrm{~m} \cdot \mathrm{d}^{-1}\right)$. $\mathrm{K}$ values were determined within one standard deviation from the average $\mathrm{K}$ value for each lithostratigraphic facies. For all realizations, the proportions for fine carbonate, alluvial fan deposits, ignimbrite, vuggy carbonate, and gypsum were 43, 24, 19, 8, and 6 percent, respectively.

Three groups of realizations with distinct horizontal to vertical stratigraphic continuity ratios $\left(\mathrm{c}_{\mathrm{h}} / \mathrm{c}_{\mathrm{v}}\right)$ were created to address the role of geologic complexity in the geometry and time sensitivity of interface response: equal continuity in both directions $\left(c_{h} / c_{v}=1\right)$, increased horizontal continuity by a factor of two $\left(c_{h} / c_{v}=2\right)$, and increased horizontal continuity by a factor of three $\left(c_{h} / c_{v}=3\right)$. 38 realizations of $K$ were created for each group. The $K_{\text {eff }}$ values for the realizations range within $5.3 \mathrm{~m} \cdot \mathrm{d}^{-1}$ and $20.3 \mathrm{~m} \cdot \mathrm{d}^{-1}$ ), according to Darcy flux estimates.

\subsection{Metrics for assessing interface geometry, sensitivity \& stability}

For each simulation, velocity vectors, solute concentration, and hydraulic head values were collected for every time step. From these results, four metrics were used to assess differences in interface geometry and the time-sensitive response in the simulation results. The first metric is the average slope of the interface, which was assessed with a linear best fit for each simulated interface after reaching an initial steady state. The second metric is the horizontal width of transition zone between fresh (i.e. $<0.04 \mathrm{~g} \cdot \mathrm{cm}^{-3}$ ) and highly saline (i.e. $>0.18$ $\mathrm{g} \cdot \mathrm{cm}^{-3}$ ) groundwater $[\mathrm{L}]$. Third, the length of the interface's migration in the horizontal direction [L] provides a metric for assessing the sensitivity of the interface following a change in recharge to the modeled aquifer. Fourth, the time-sensitivity of the interface's response following a perturbation in recharge is characterized by a time constant as defined by:

$$
\frac{[m]_{\mathrm{f}}}{[m]_{\mathrm{i}}}=e^{-\mathrm{kt}}
$$

where the rate of change in the mass of solute is equal to an exponential curve (i.e. "efolding time"). This response is assessed via the rate of change in the total mass of modeled solute in the domain. For the purpose of this study, the e-folding time serves as a characteristic of the response rate, with the amount of time corresponding to the relative speed of response to a perturbation in recharge. We additionally assess flow topology using the Okubo- 
Weiss (OW) method to provide a mechanistic explanation for the simulation results (de Barros et al., 2012; Geng et al., 2020).

\section{Results}

\subsection{Geometry \& dynamic response of the hydrostratigraphic framework of Salar de Atacama}

Figure 4 illustrates the solute concentration values, hydraulic head field, and velocity field of both the HSF of SdA and the homogeneous model that represents the $\mathrm{K}_{\mathrm{eff}}$ of the HSF. For the homogeneous results, solute concentration values show a consistent transition zone width from 0 to $0.2 \mathrm{~g} \cdot \mathrm{cm}^{-3}$ with depth, though the upper 50 meters of the model near the area of modeled evaporation appears to increase in transition zone width. The hydraulic head and flow velocity fields reflect the geometry of concentration values, with higher head and velocity values at depth in the modeled inflowing freshwater, forcing fluid convection and upwelling. Both the hydraulic head and velocity fields have a spatially even distribution in the gradual decline from highest to lowest values at depth. Concentration values in the homogeneous model diverge from observed field conditions by several kilometers at depth.

Compared to its homogeneous counterpart, results from the heterogeneous model that represent the HSF of SdA have a shallower interface that conforms with observed concentration values within 10 meters at depth. Numerical results shown in Figure 4 also indicate a varying width of the brine-to-freshwater transition zone from sharp to diffuse. The hydraulic head field similarly expresses sharp to diffuse transitions from high to lower values. Despite the variations in hydraulic head at depth, the majority of the high flow velocity is concentrated in the upper surficial layer of the domain and coincides with the laterally inflowing recharge. The e-folding time in response to inflow perturbations is larger by at least a factor of three for the HSF model when compared to the homogeneous model (Figure 8). The total distance that the interface travels as a result of a change in inflow, as assessed through the movement of the 0.5 isoconcentration line, likewise exhibits a distinct difference between the heterogeneous and homogeneous models, with interface travel through permeable pathways within the heterogeneous model.

\subsection{Geometry \& dynamic response of the geostatistical realizations of hydraulic con- ductivity to changes in inflow}

Simulations with equally probable $\mathrm{K}$ distributions produce physical and time-sensitive results that diverge from their homogeneous counterparts and show a statistically significant relationship with stratigraphic continuity in a geologically complex environment (Table 2). The simulations show interface geometries that decrease in slope as $c_{h} / c_{v}$ increases (Figure 6). The range of locations for the interface for each group of geostatistic realizations is shown in Figure 7. Homogeneous models with equivalent $\mathrm{K}_{\mathrm{eff}}$ as the realizations produce interface geometries that are steeper by at least a factor of two and in some cases by an order of magnitude. The average slope for each group of realizations increases by approximately half a degree for every increase in $c_{h} / c_{v}$ by a factor of one. Similarly, the thickness of the transition zone between saline and freshwater also has a pattern of generally decreasing while expressing more variation in diffuse versus sharp concentration gradients as horizontal continuity increases, whereas the homogeneous models show a consistently thicker transition zone (Figure 8).

The density-dependent dynamics in the geostatistical realizations exhibit a pattern for the sensitivity of the interfaces. Increased $c_{h} / c_{v}$ in the realizations yields an increase in the overall length of interface migration and thus presumably creates an increase in the response of density-dependent flow to changes in subsurface later inflow into an aquifer. An increase in the horizontal continuity also results in longer time constants in the exponential decay of an interface's migration rate (Figure 9). From least to most continuous, each group of realizations respectively yielded average interface migration of $3586 \pm 2323 \mathrm{~km}, 3816 \pm 1679 \mathrm{~km}$, and 
a)
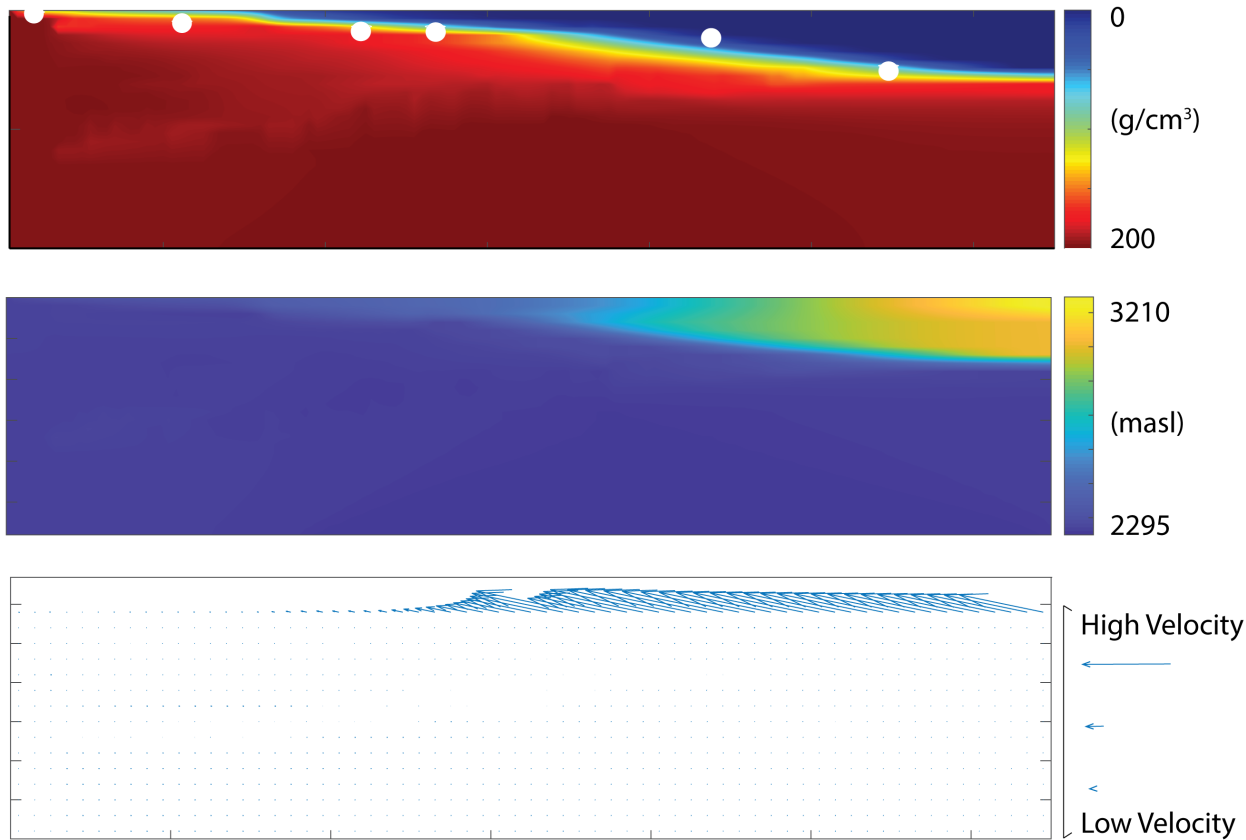

b)
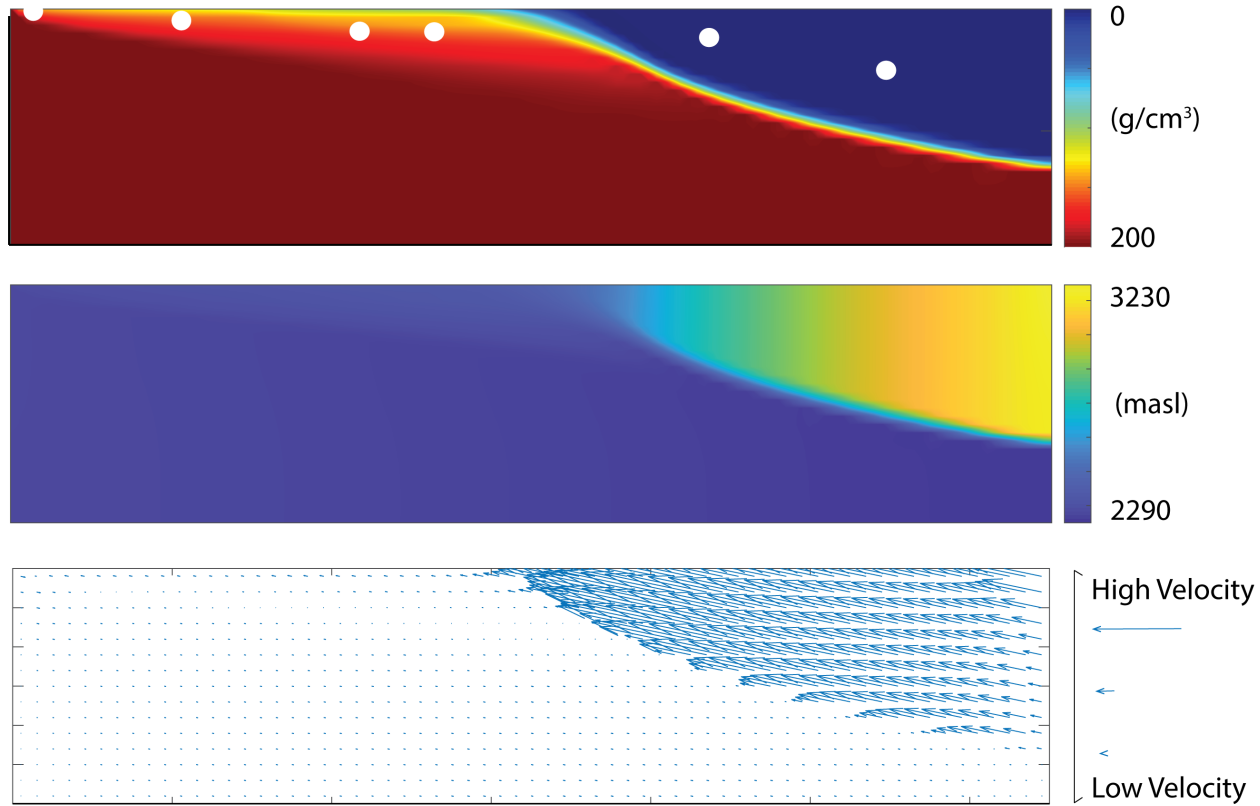

Figure 4. Visual comparison of the distribution of concentration $\left(\mathrm{g} \cdot \mathrm{cm}^{-3}\right)$ of dissolved salt in the modeled aquifer, the hydraulic head, and the velocity vectors for both the a) heterogeneous model based on the hydrostratigraphic framework and $b$ ) the homogenous model with the same $\mathrm{K}_{\mathrm{eff}}$. White dots indicate the location of the observed interface in the wells. 
Higher continuity

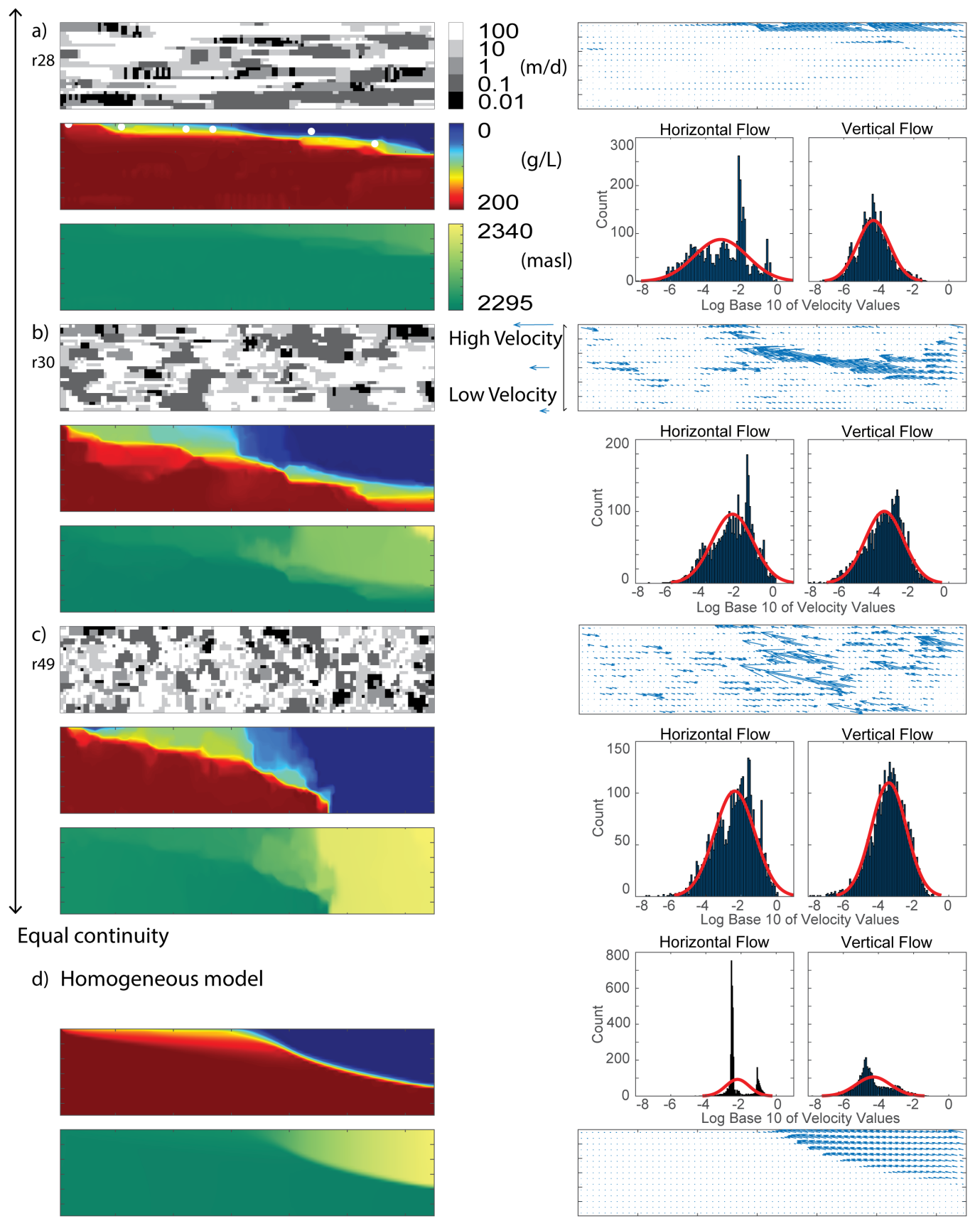

Figure 5. Results for one example in each group of $K$ realizations, with a) $\left.\left.c_{h} / c_{v}=3, b\right) c_{h} / c_{v}=2, c\right) c_{h} / c_{v}=1$, and d) homogeneous model. For each example, clockwise from the upper left corner, the K distribution in $\mathrm{m} / \mathrm{d}$, flow velocity vectors, flow velocity distribution $\left(\log _{10} \mathrm{~m} / \mathrm{d}\right.$ ), hydraulic head distribution (masl), and salinity distributions (g/L) are shown. White points are observed interface locations. 


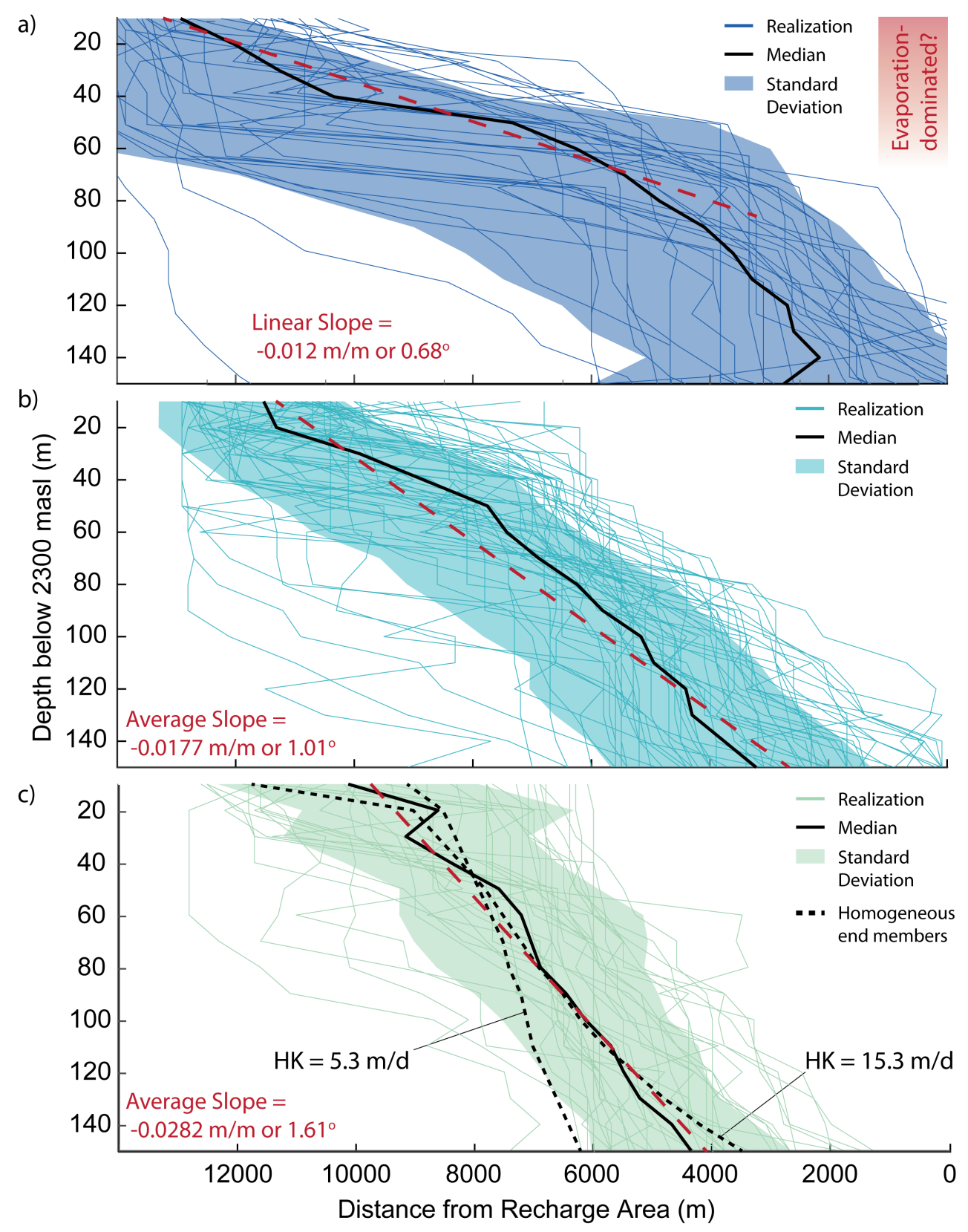

Figure 6. Distance of the 0.5 concentration point from the recharge area with depth for each group of geostatistical of hydraulic conductivity. Each group of realizations is separated based on degree of continuity, with increased horizontal continuity by a factor of three (dark blue), increased horizontal continuity by two (light blue), and equal continuity (green) in order from top to bottom. The value for the linear best fit (dashed red) for the median (solid black) of each group is listed in the lower right corner of the graphs. The shaded region is the standard deviation. 


\begin{tabular}{llllll}
\hline Metric & Increase v. Decrease & Group Comparison & Result & Critical Value & Significance Level \\
\hline Geometry & - & 1 and 2 & 4.53 & 1.67 & 0.05 \\
Geometry & - & 2 and 3 & 3.70 & 1.66 & 0.05 \\
Geometry & - & 1 and 3 & 6.15 & 1.67 & 0.05 \\
Time Constant & Increase & 1 and 2 & 0.38 & 1.3 & 0.1 \\
Time Constant & Increase & 2 and 3 & 1.48 & 1.3 & 0.1 \\
Time Constant & Increase & 1 and 3 & 1.75 & 1.66 & 0.05 \\
Time Constant & Decrease & 1 and 2 & 1.05 & 1.3 & 0.1 \\
Time Constant & Decrease & 2 and 3 & 1.46 & 1.3 & 0.1 \\
Time Constant & Decrease & 1 and 3 & 2.72 & 1.66 & 0.05
\end{tabular}

Table 2. Statistical significance of variance in metrics by group of HK realizations, with the result and corresponding critical value and significance level. Metric results related to recharge increase versus decrease noted where applicable. Groups are distinguished by $c_{h} / c_{v}$ value.

a)

Increased Inflow

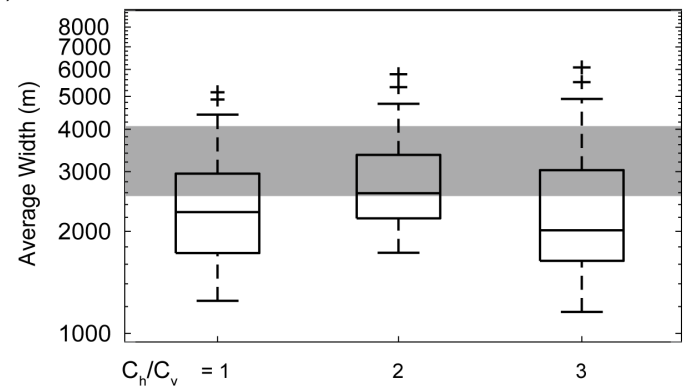

b)

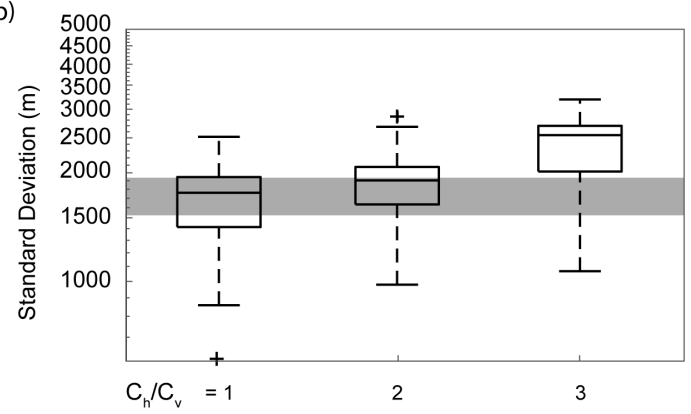

Decreased Inflow
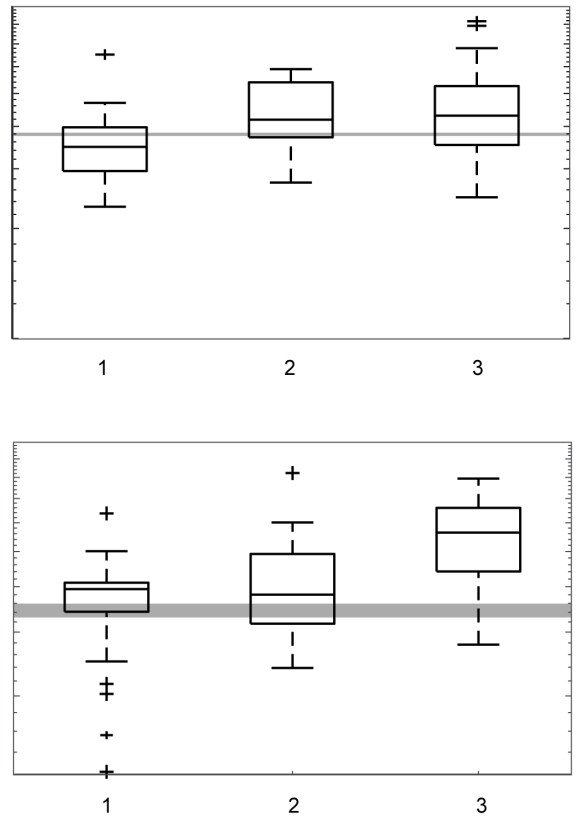

Figure 7. The distribution of a) the average and b) the standard deviation of transition zone widths from brackish $\left(0.04 \mathrm{~g} \cdot \mathrm{cm}^{-3}\right)$ to brine $\left(0.18 \mathrm{~g} \cdot \mathrm{cm}^{-3}\right)$ for the geostatistical realizations of hydraulic conductivity, separated based on horizontal hydrostratigraphic continuity as compared to vertical continuity. Gray shaded area is the range of homogeneous values. 

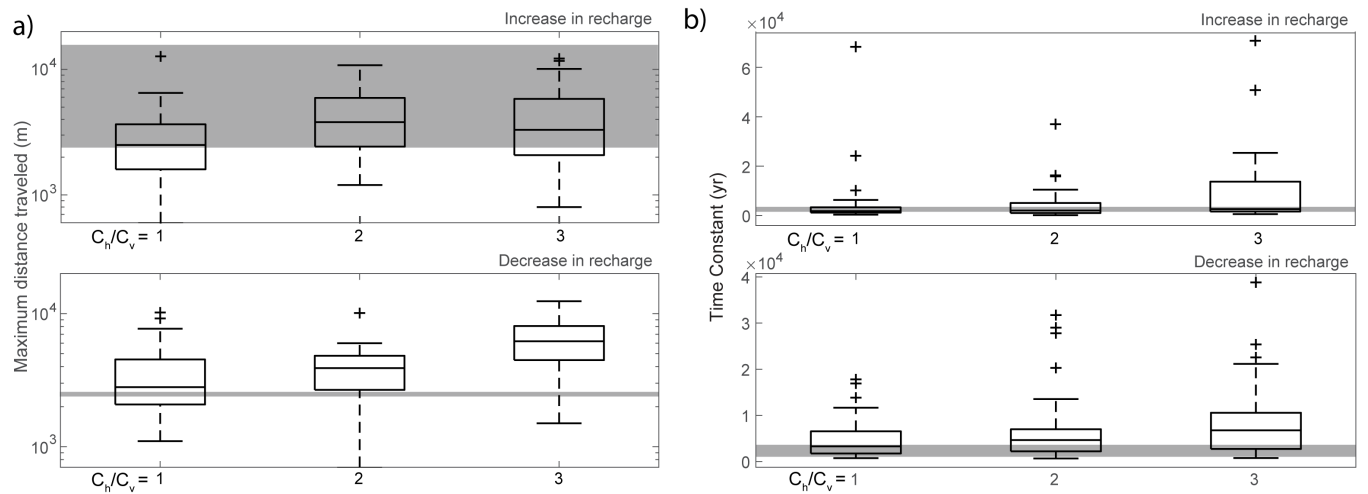

Figure 8. The distribution of a) maximum distance of interface travel and b) time response to a change in inflow for the geostatistical realizations of hydraulic conductivity, separated based on $C_{h} / C_{v}$. Above statistical analysis represent an increase in inflow and the lower plots represent results from a decrease in inflow. The gray shaded area indicates the homogeneous model results.

$6548 \pm 2926 \mathrm{~km}$ following a decrease in recharge. This equals an increase of $48 \%$ and $31 \%$ in average migration for each respective increase in $\mathrm{c}_{\mathrm{h}} / \mathrm{c}_{\mathrm{v}}$. For e-folding times in the interface response, the average time constant was $4804 \mathrm{yr}, 5754 \mathrm{yr}$, and $9881 \mathrm{yr}$ for each group from least to most in $\mathrm{c}_{\mathrm{h}} / \mathrm{c}_{\mathrm{v}}$, creating a $20 \%$ and $72 \%$ increase in time for each respective increase in $c_{h} / c_{v}$. The observed time response differences are statistically significant between the groups $c_{h} / c_{v}=1$ and $c_{h} / c_{v}=3$ to a significance level of 0.1 ; between groups $c_{h} / c_{v}=1$ versus $c_{h} / c_{v}=3$ and $\mathrm{c}_{\mathrm{h}} / \mathrm{c}_{\mathrm{v}}=2$ and $\mathrm{c}_{\mathrm{h}} / \mathrm{c}_{\mathrm{v}}=3$ to a significance level of 0.05 (table 2). Comparatively, the brine-to-freshwater interface migration within the homogeneous models exhibit less sensitivity in terms of the amount of interface movement and decreased time required to reach a new steady state subsequent to being exposed to the same perturbations in recharge.

\section{Discussion}

\subsection{Geometry $\&$ inferred density-driven dynamics of the brine-to-freshwater inter- face at Salar de Atacama}

This study represents the most robust attempt to numerically simulate and accurately capture the geometry of the brine-to-freshwater interface along the southeastern margin of the halite nucleus at $\mathrm{SdA}$. It also represents the most accurate 2-D hydrostratigraphic interpretation of the southeastern margin. Simulation results of the K field resulting from the hydrostratigraphic interpretation suggest that subsurface heterogeneity impacts density-dependent dynamics to the degree that it shallows the interface geometry and focuses flow where the interface intersects conduits of relatively higher K. Focused discharge represented by the modeled velocity values occur along highly continuous preferential pathways, further suggesting that continuity in hydrostratigraphic units may serve as a controlling factor in the impact of heterogeneity. These results therefore provide a basis for investigating not only the role of heterogeneity, but specifically the degree to which conductivity impacts density-dependent dynamics and associated solute transport. While the motivations behind previous simulations of the basin may not have included the creation of an accurate density-dependent basin-scale simulation, results from this study suggest that locating and defining the locations and prevalence of hydraulically conducive media hold value in defining density-dependent dynamics (Marazuela et al., 2018). Thus sitespecific observations potentially represent a relationship between heterogeneity and densitydependent sensitivity to perturbations in recharge that require further investigation, which is what this current work presents. 


\subsection{Impact of increased hydrostratigraphic continuity in heterogeneity on density- driven dynamics $\&$ resulting interface sensitivity}

Results from the series of $\mathrm{K}$ realizations demonstrate that horizontal continuity in hydrostratigraphic heterogeneity decreases the slope of the brine-to-freshwater interface (Figure 6). The decreased interface slope results from decreased vorticity-dominated flow, as indicated by OW values (Figure 9). The simulations also support that increased horizontal continuity in hydrostratigraphic units generally decrease the average thickness of the transition zone, while also increasing the variability between a sharp and diffuse transition zone (Figure 7). This supports previous findings of variably diffuse behavior of brine-to-freshwater interfaces in heterogeneous media (Michael et al., 2016). Increased variability in transition zone thickness likely results from increased preferential pathways in the horizontal direction, which is supported by the increased prevalence of strain-dominated flow in areas where the interface intersects conduits of flow (Figure 9). Since increased versus decreased perturbations in recharge have distinct effects on the thickness of the transition zone, it is important to account for different mechanisms involved in the physical expression of an interface. Increased recharge does not impact the average transition zone thickness because the majority of interface movement is controlled by the interplay between head and density gradients, while decreased recharge results in all model results exhibiting similar average transition zone thickness regardless of horizontal hydrostratigraphic continuity because diffusion is a primary mechanism for solute transport.

The simulated interface responses to changes in hydraulic head are consistent with previous density-dependent interface modeling where the interface adjusted in location based on hydraulic head variations (Yechieli, 2000; Yechieli et al., 2001; Liu et al., 2014). This study further indicates that increased hydrostratigraphic continuity increases density-driven sensitivity of groundwater flow in terms of the extent of interface travel and the time-sensitive response for the interface to reach a new dynamic steady state following a perturbation in recharge (Figure 8). The shift of the simulated aquifer's density-driven dynamics toward more strain-dominated flow accounts for this change in sensitivity (Figure 9). The importance of continuity in heterogeneity is supported by comparison with homogeneous models, which have results that are comparatively limited in both length of interface movement and in the time-sensitive response, though they share the same $\mathrm{K}_{\mathrm{eff}}$ and anisotropy values as the series of $\mathrm{K}$ realizations (Figure 8). The series of $\mathrm{K}$ distributions with $\mathrm{c}_{\mathrm{h}} / \mathrm{c}_{\mathrm{v}}=1$ result in similar time responses when compared to the homogeneous results because the connectivity of vorticity-dominated flow regimes at depth allow density-dependent flow to equilibrate at similar rates. Increasing horizontal continuity in hydrostratigraphy limits the vertical connectivity of vorticity-dominated flow regimes and promotes strain-dominated flow, which result in the prolonged density-driven response.

Horizontal continuity in hydrostratigraphic units controls flow topology in density-dependent dynamics, and this relationship is responsible for the resulting variable sensitivity of the interface. An increase in $c_{h} / c_{v}$ leads to an increase in the prevalence of highly conductive preferential pathways in the horizontal direction which thus increases the potential for the disequilibrium of hydraulic head in vertical direction. Higher disequilibrium results in longer timescales required for density-dependent flow to reach a new stable position. Sensitivity likewise increases in terms of the length of interface migration because of increased preferential pathways facilitate sensitivity to density-driven hydraulic head variations and thus trigger strain-dominated flow where the interface meets high-K units. OW analysis suggests that strain-dominated flow is focused along the brine-to-freshwater interface where it intersects with high-K preferential pathways (Figure 9). The distribution of OW values also indicate elongated diffusion-dominated flow in the horizontal direction as $c_{h} / c_{v}$ increases. These two observations indicate that while increased $c_{h} / c_{v}$ creates horizontally elongated diffusive flow conditions that increase hydraulic disparities in the vertical direction and therefore decrease the response time for the system as a whole, the interface-specific locations of conduits for preferential flow host the density-dependent discrepancy in hydraulic head that drives the saline intrusion. 
Simulated evaporation remained constant throughout the study, and an analysis of the impact of evaporation on the brine-to-freshwater interface sensitivity is beyond the scope of this study. However, it is possible to infer the potential impact from evaporation on the interfacebased sensitivity analysis. A remarkably consistent characteristic of the response to changes in inflow was the relatively unchanged interface position within the modeled area of evaporation. When confluence with the surface intersected the evaporation area, interface migration in response to perturbations in recharge was smaller by almost an order of magnitude compared to the average length of migration of the cells at depth. This observation confirms the importance of considering potential evaporation in arid aquifers with abundant brine.

\subsection{Implications for future simulations \& accurate physical expressions of brine-to- freshwater interfaces in arid basins}

Increased horizontal hydrostratigraphic continuity creates brine-to-freshwater interface dynamics that shallow the interface and increase the variability in transition zone thickness, which differs from predictions based on homogeneous numerical simulations of density-dependent groundwater flow (Figure 10). The direct relationship between lateral hydrostratigraphic continuity in subsurface heterogeneity and interface geometry indicates that heterogeneity represents a primary control on brine-bearing systems with subsurface lateral recharge as the primary long-term recharge mechanism. The relationship between horizontal continuity in geologic heterogeneity and variability in transition zone thickness indicates that representations of hydrostratigraphic heterogeneity is valuable for realistic expressions of the interface thickness. This is especially critical for arid basins, where the development of transitional evaporite facies creates locally continuous units (Vásquez et al., 2013). In salt flat environments, the prevalence of continuous boundaries of evaporite series against higher-permeability facies may account for the shallowing behavior of observed interfaces in certain locations where high evaporation dominates. Brine-bearing aquifers with continuous stratigraphic contacts between high and low permeability units may develop distinctly shallower interface geometries than traditional homogeneous or simplistic models, where higher-K units act as high-K conduits for fluid flow. This is especially true for depositional environments and marginal zones adjacent to developed salars. These observations are particularly relevant to brine-bearing aquifers that do not experience additional hydraulic fluctuations like tidal forcing and wave-induced circulation, such as coastal aquifers.

This study also indicates evaporation as a control in interface expression in arid and inland basins that highlight the necessity for high resolution of hydrostratigraphic accuracy in numerical simulations. Results indicate that the trend of an increasingly shallowing interface with increasing horizontal continuity is also prevalent in arid basins with high rates of evaporation, where discharge controls the hydraulic head distribution and promotes vertical and upwards fluid migration over any lateral sensitivity to recharge. This evaporation-dominant flow pattern occurs through the upper 50 meters in all simulations in this study. However, due to more vertically conductive flow, the homogeneous models tend to exhibit more apparent evaporationdriven expressions. However, while evaporation clearly impacts interface geometry to a degree, the extent to which evaporation controls interface dynamics when coupled with geologic heterogeneity and recharge requires further analysis.

These findings hold several implications for the future of numerically simulating densitydependent flow in arid and endorheic basins. Current density-dependent modeling of such basins typically produces simple representations of an aquifer, using homogeneous changes in anisotropy or simple layers with differing hydraulic conductivity values in order to shallow the interface geometry and match model results with observed field conditions. Considering that recharge may decrease in arid climates as a result of climate change, it is prudent to focus on the impacts of decreased inflow in the models (Wang et al., 2018). Modeling suggests that brine-tofreshwater interface migration distances are between $10-35 \%$ more sensitive to a decrease than an increase in inflow. These reactions highlight the importance of accounting for projected climatedriven changes in the hydrologic budgets of arid basins. Without considering the geologic com- 
a) $C_{h} / C_{v}=3$
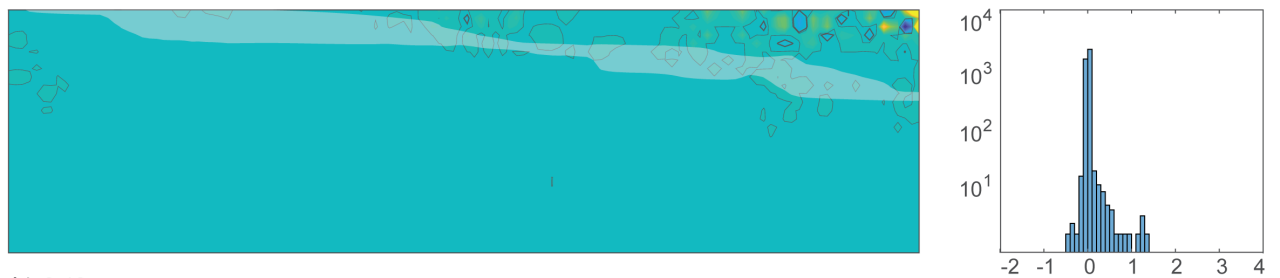

b) $C_{h} / C_{v}=2$
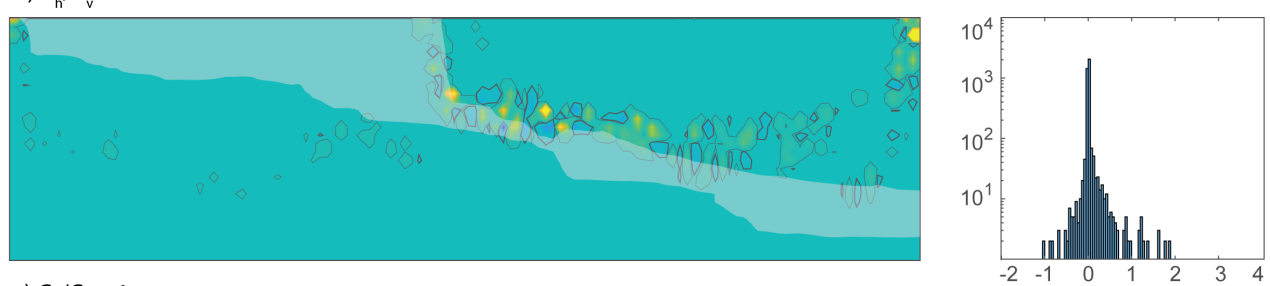

c) $C_{h} / C_{v}=1$
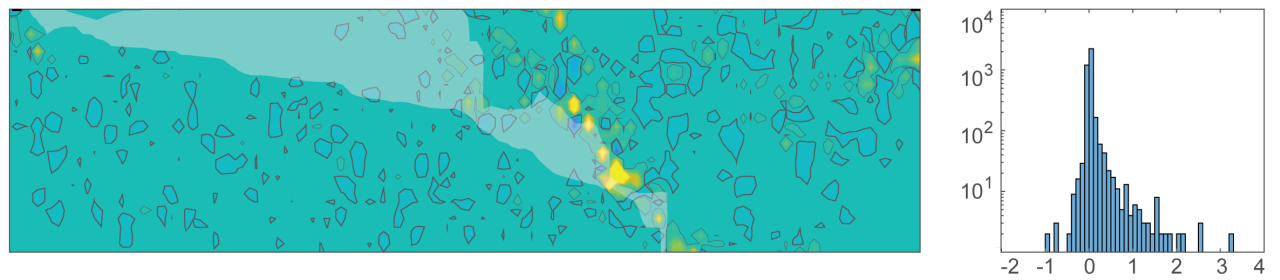

d) Homogeneous
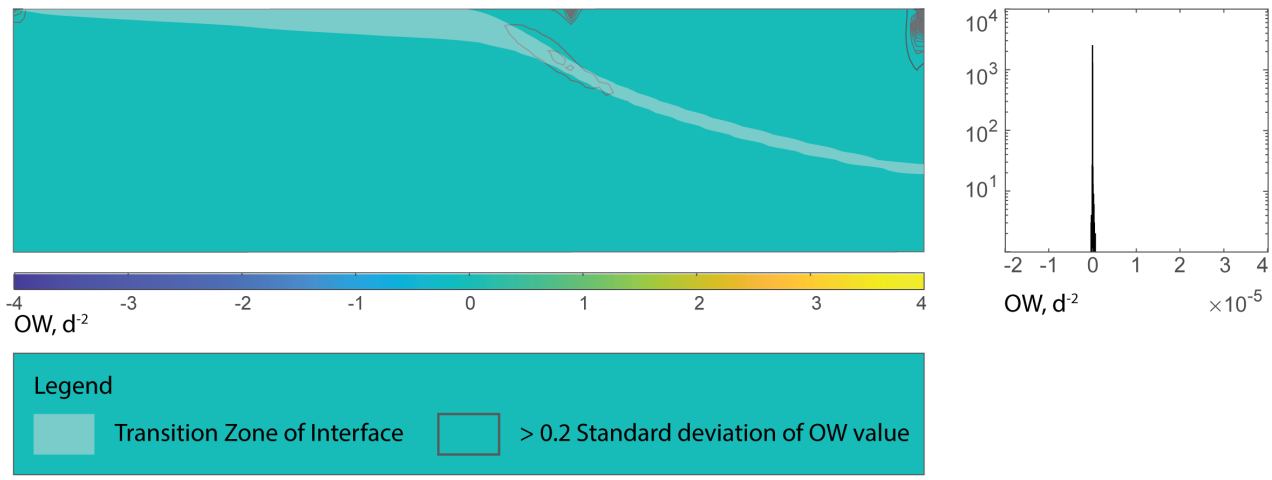

Figure 9. Spatial distributions and histograms of $\mathrm{OW}$ values for the same example simulations for each group from figure 5 , with a) $\left.c_{h} / c_{v}=3, b\right) c_{h} / c_{v}=2$, c) $c_{h} / c_{v}=1$, and d) homogeneous model. The white shaded areas indicate the physical location of the simulated interface's transition zone. 
plexity or continuity of hydrostratigraphic units in an aquifer, such models result in conditions that may not produce either accurate geometries or reliable saline intrusion predictions. Thus homogeneous models are not suitable for understanding an aquifer's response to climate-driven changes in recharge. While simple changes in anisotropy may produce interface slopes that approach observed conditions, they do not account for local variation in the geometry, including the observed shallowing trend seen in the upper 50 meters of the aquifer of SdA. This sensitivity analysis documents that this shallowing trend impacts the density-driven response to changes in inflow. Accurate estimations of saline intrusion therefore require precise modeling of geologic heterogeneity in order to more effectively assess geometry as well as response to changes in recharge and discharge mechanisms.

\subsection{Implications on future simulations of transient density-driven flow in brine-bearing aquifers}

The majority of aquifers host a degree of subsurface heterogeneity regardless of depositional environment. Results from this study elucidate the time-sensitivity of the interface's response to recharge which may be applicable to all brine-bearing aquifers. Coastal environments have specific conditions that define the brine-to-freshwater interface and seawater circulation, but questions remain regarding the extent to which continuity in heterogeneity impacts the rates and distribution of subsurface groundwater discharge, especially in response to variations in recharge from inland aquifers (Russoniello et al., 2013). Horizontal hydrostratigraphic continuity in heterogeneity addresses the question of geologic impact on interface sensitivity regardless of other physical characteristics that impact brine-bearing aquifers. Increased continuity in hydrostratigraphic units increases the time required for an interface to reach a new dynamic steady state by between 5 to $30 \%$. Longer, high-permeability conduits result in preferential pathways with localized hydraulic conditions that may differ from the effective hydraulic conductivity. These pathways create an unequal response in hydraulic head throughout an aquifer, which then leads to longer response times as differences in head require more time to stabilize throughout the flow field. This study thus suggests that continuity increases the timescales over which long-term variations in subsurface lateral recharge will manifest in saline groundwater intrusion, despite a range of other factors impacting brine-bearing aquifers such as coastal environments. Since high horizontal continuity is a common feature in depositional environments, such as salt flats specifically, and arid, endorheic basins in general, homogeneous or simplistic modeling methods underestimate both the total amount of possible saline intrusion and the timescale at which migration can occur. This implies that predictions and analysis of transient saline intrusion in all brine-bearing aquifers must account for subsurface heterogeneity, especially within interface-adjacent areas.

\subsection{Limitations of the simulation framework}

Randomized distributions of HK may not exactly represent the asymmetrical depositional environments of salt flats. Evaporite sequences produce geochemically zoned areas that often abut facies with distinctly different hydrogeologic characteristics (Vásquez et al., 2013). This creates an asymmetric distribution of hydraulic conductivities, which randomized distributions of hydraulic conductivity may not accurately represent. Therefore, analysis of time constant values is limited to comparison among models. While a simple comparison with the HSF model indicates that most of the time constant values may seem plausible for playa environments, the question of the realizations' geologic plausibility impedes the ability to rely on time constant values produced from these models as globally realistic scenarios.

Several hydrogeologic conditions remain homogeneous in the framework for the simulations, despite their direct correlation to changes in hydraulic conductivity. Specific yield, porosity, and anisotropy would be intrinsically heterogeneous, yet they remain consistently homogeneous for computational simplicity given the number of realizations in the study's scope. Constant and homogeneous values for these variables may underrepresent the full impact of subsurface heterogeneity. 


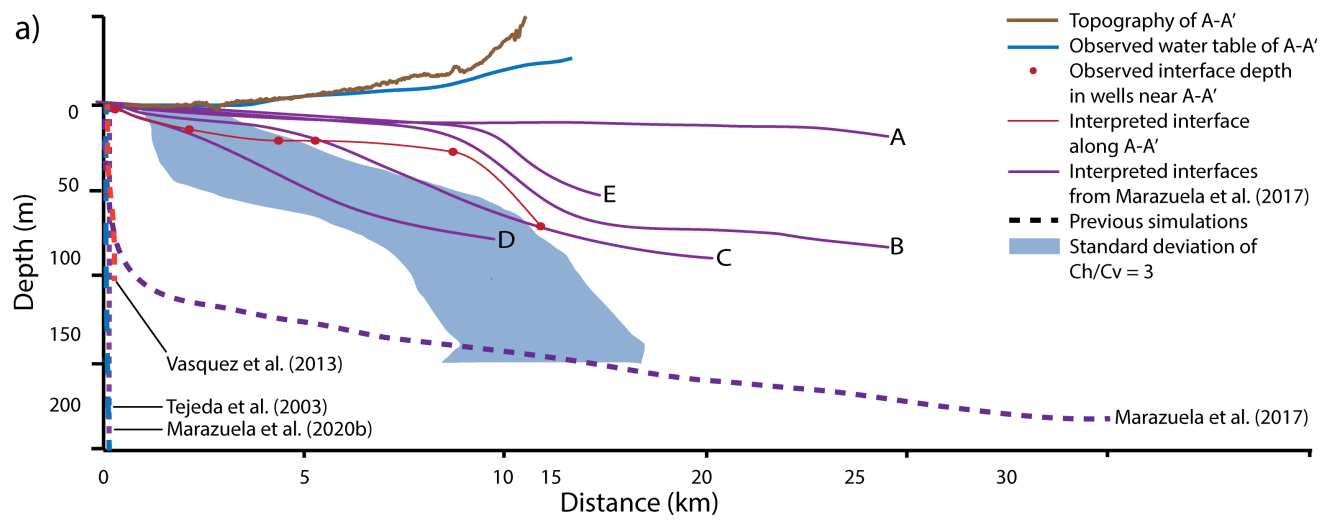

b) Single Density Conditions

c) Density-driven \& Homogeneous
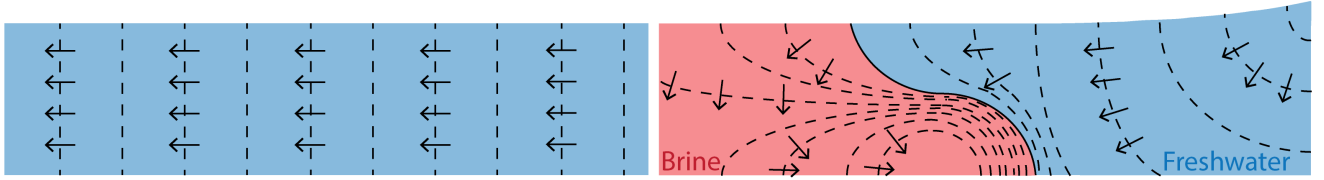

d) Density-driven \& Heterogeneous

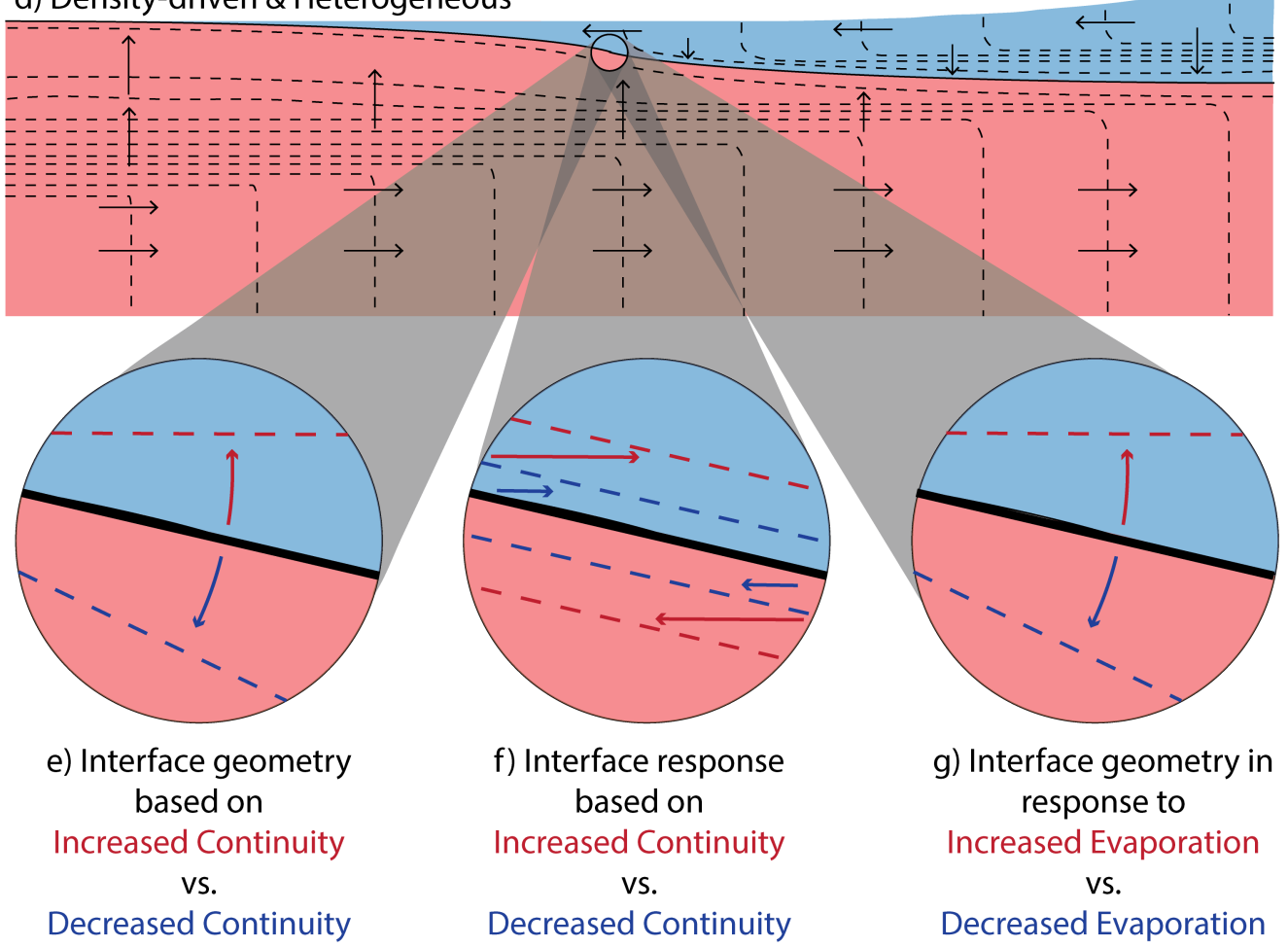

Figure 10. Conceptual illustration of results from observations of simulations with different distributions of hydraulic conductivity, with a) a comparison of this study's simulations with previous studies, b) a homogeneous, single-density flow with black dashed lines showing potentiometric head contours, c) a homogeneous, variable-density flow model where the main determinant of interface geometry is the difference in density, and d) a heterogeneous model where the geometry of the interface is dependent on density and e) the extent of continuity in K. f) The sensitivity of the interface is also sensitive to continuity, g) The extent and rate of evaporation also has a likely impact on interfave geometry. 


\section{Conclusion}

Constraining the physical impacts of heterogeneity on the density-driven dynamics that control brine-to-freshwater interface migration and sensitivity is crucial for managing groundwater resources of brine-bearing aquifers in anticipation of climate-driven change. Homogeneous numerical simulations of density-driven flow fail to capture accurate geometry and presumably the dynamics of such interfaces. Aiming to develop a more accurate framework for the mechanisms driving density-driven fluid flow in arid basins, we assess the extent to which lateral hydrostratigraphic continuity impacts physical characteristics and time-sensitive behavior of the interface. To constrain the impact of continuity in geologic complexity, we employ a series of realizations of $\mathrm{K}$ with varying horizontal continuity. Following a perturbation in the simulated recharge to grioundwater flow through each realization, we collect the the interface slope, total distance that the interface travels, and the time required for the interface to reach a new steady-state in terms of an "e-folding" time constant.

The K distribution from the HSF of SdA produced a modeled interface that matched the observed location within 10 meters to a depth of 100 meters. Solute distribution results from the homogeneous counterpart of the HSF diverged from observed values. Simulated responses to perturbations in recharge from the HSF were also longer in both interface migration and migration response times than the homogeneous results. Results from the series of realizations of $\mathrm{K}$ distributions investigate whether the comparative observations can be attributed to hydrostratigraphic continuity in heterogeneity. Simulated values of concentration and hydraulic head best match observed conditions from SdA for the realizations with the strongest trend in horizontal continuity. Results further show a decrease in the slope of the interface as horizontal hydrostratigraphic continuity increases in the heterogeneous realizations, indicating that the improved matching of observed and simulated values is linked to the shallowing effect of increased continuity. This suggests that the relationship between the different hydrostratigraphic units and the resulting localized disequilibrium from those preferential pathways controls the distribution and sensitivity of hydraulic head. Our findings show a relationship between hydrostratigraphic continuity in heterogeneous environments and the resulting brine-to-freshwater interface response dynamics, with interface migration increasing by an order of magnitude and migration response times increasing by a factor of three when horizontal hydrostratigraphic continuity increases by a factor of two.

The results suggest that horizontal hydrostratigraphic continuity in heterogeneity impacts saline intrusion and therefore must be accounted for when modeling at all scales. The degree to which both anthropogenic extraction and ET coupled with hydrostratigraphic continuity impact interface dynamics remains undefined in arid basins. Future modeling initiatives using a similar geostatistical approach can address possible relationships on these different strains to brine-bearing aquifers. Arid regions throughout the world are experiencing strains on groundwater resources as anthropogenic exploitation and climate-driven aridity increases. This modeling approach constrains the density-driven dynamics of brine-to-freshwater interfaces in arid regions in response to climate-driven changes in recharge by establishing a first-order control between hydrostratigraphic continuity and density-driven dynamics. This study also confirms the importance of controlling time-sensitive reactions to changes in recharge for all brine-bearing aquifers.

\section{Summary}

Numerical simulations of density-driven groundwater flow along brine-to-freshwater interfaces that utilize equally probable representations of hydrostratigraphic heterogeneity indicate that geometry as well as the sensitivity and stability of interfaces depend on continuity of geologic units. While increased horizontal continuity leads to shallower and more anomalous expressions of the interface, increased continuity also results in higher sensitivity and more instability. Variable flow fields resulting from high hydraulic conductivity flow paths create an unstable environment in which the lack of connectivity prevents the most efficient reaction 
in an aquifer in response to hydrologic changes. The results indicate that developing a hydrostratigraphic conceptualization without identifying both the distribution of conductivity and the location of preferential flow risks the loss of accuracy in interpretations of density-driven fluid dynamics. These findings have implications for accurately assessing the risk of saline intrusion and the sustainability of groundwater-fed shallow pool ecosystems in brine-bearing aquifers.

\section{Acknowledgments}

The authors would like to thank the Albemerle Corporation for supporting our ongoing research in order to further develop the understanding of density-driven flow dynamics. Special thanks to Jorge Garcia for his acumen and encouragment of our work. The data and model results presented may be obtained through the University of Massachusetts Data Repository. Funding for this work was primarily provided by Albemerle Corporation and research on the sediment cores was supported by the National Science Foundation (grant number EAR1443226).

\section{References}

Bailey, R. (2015). Quantifying transient post-overwash aquifer recovery for atoll islands in the western pacific. Hydrological Processes, 29, 4470-4482.

Bear, J. (1972). Dynamics of fluids in porous media. New York: Elsevier Science, 53.

Boutt, D. F., Hynek, S., A, M. L., \& G, C. C. (2016). Rapid recharge of fresh water to the halite-hosted brine aquifer of salar de atacama, chile. Hydrological Processes, 30, 4720-4740.

Carle, S. (1999). T-progs: Transition probability geostatistical software. University of California, Davis, 1-78.

Carmona, V., Pueyo, J. J., Taberner, C., Chong, G., \& Thirlwall, M. (2000). Solute inputs in the salar de atacama (n. chile). Journal of Geochemical Exploration, 69-70, 449-452.

Condon, L. E., \& Maxwell, R. M. (2019). Simulating the sensitivity of evapotranspiration an streamflow to large-scale groundwater depletion. Sci. Adv., 5, 1-9.

Corenthal, L., Boutt, D. F., Hynek, S., \& Munk, L. A. (2016). Regional groundwater flow and accumulation of a massive evaporite deposit at the margin of the chilean altiplano. Geophysical Research Letters, 43(15), 8017-8025.

de Barros, F., Dentz, M., Koch, J., \& Nowak, W. (2012). Flow topology and scalar mixing in spatially heterogeneous flow fields. Geophysical Research Letters, 39, 1-5. doi: 10 $.1029 / 2012$ GL051302

Duffy, J., \& Hassan, S. (1988). Groundwater circulation in a closed desert basin: topographic scaling and climatic forcing. Water Resources Research, 24(10), 1675-1688.

Eugster, H. P. (1980). Geochemistry of evaporitic lacustrine deposits. Ann. Rev. Earth Planet. Sci., 8, 35-63.

Fan, Y., Duffy, C., \& Oliver, D. (1996). Density-driven groundwater flow in closed desert basins : field investigations and numerical experiments. Journal of Hydrology, 196, 139-184.

Ferguson, G., \& Gleeson, T. (2012). Vulnerability of coastal aquifers to groundwater use and climate change. Nature Climate Change, 2, 342-345.

Gelhar, L. W., Welty, C., \& Rehfeldt, K. R. (1992). A critical review of data on field-scale dispersin in aquifers. Water Resources Research, 28(7), 1955-1974.

Geng, X., \& Boufadel, M. C. (2015). Impacts of evaporation on subsurface flow and salt accumulation in a tidally influenced beach. Water Resources Research, 51, 5547-5565.

Geng, X., Boufadel, M. C., Rajaram, H., Cui, F., Lee, K., \& An, C. (2020). Numerical study of solute transport in heterogeneous beach aquifers subjected to tides. Water Resources Research, 56, 1-20.

Haitjema, H. M., \& Mitchell-Bruker, S. (2005). Are water tables a subdued replica of the topography? Ground Water, 43(6), 781-786.

Hamann, E., Kohfahl, C., Prommer, H., \& Simmons, C. T. (2015). Numerical investigation of coupled density-driven flow and hydrogeochemical processes below playas. Water 
Resources Research, 51, 9338-9352.

Heiss, J., Post, V., Laattoe, T., Russoniello, C., \& Michael, H. (2017). Physical controls on biogeochemical processes in intertidal zones of beach aquifers. Water Resources Research, 53, 9225-9244. doi: 10.1002/2017WR021110

Heiss, J. W., \& Michael, H. A. (2014). Saltwater-freshwater mixing dynamics in a sandy beach aquifer over tidal, spring-neap, and seasonal cycles. Water Resources Research, 50, 6747-6766.

Hernández-López, M. F., Gironás, J., Braud, I., Suárez, F., \& Muñoz, J. F. (2014). Assessment of evaporation and water fluxes in a column of dry saline soil subject to different water table levels. Hydrological Processes, 28, 3655-3669.

Houston, J. (2009). A recharge model for high altitude, arid, andean aquifers. Hydrological Processes, 23, 2383-2393.

Houston, J., Butcher, A., Ehren, P., Evans, K., \& Godfrey, L. (2011). The evaluation of brine prospects and the requirement for modifications to filing standards. Economic Geology, 106(7), 1125-1239.

Jordan, T. E., Mpodozis, C., Muñoz, N., Blanco, N., Pananont, P., \& Gardeweg, M. (2004). Cenozoic subsurface stratigraphy and structure of the salar de atacama basin, northern chile. Journal of South American Earth Sciences, 122-146.

Jordan, T. E., Muñoz, N., Hein, M. C., Lowenstein, T., Godfrey, L., \& Yu, J. (2002). Active faulting and folding without topographic expression in an evaporite basin, chile. Bulletin of the Geological Society of America, 114(11), 1406-1421.

Ketabchi, H., Mahmoodzadeh, B., Ataie-Ashtiani, B., \& Simmons, C. (2016). Sea-level rise impacts on seawater intrusion in coastal aquifers: Review and integration. Journal of Hydrology, 535, 235-255.

Klammler, H., Jawitz, J., Annable, M., Yaquain, J. A., Hatfield, K., \& Burger, P. (2020). Decadal scale recharge-discharge time lags from aquifer freshwater-saltwater interactions. Journal of Hydrology, 582, 1-13. doi: 10.1016/j.jhydrol.2019.124514

Konikow, L. F., Akhavan, M., Langevin, C. D., Michael, H. A., \& H, S. A. (2013). Seawater circulation in sediments driven by interactions between seabed topography and fluid density. Water Resources Research, 49(3), 1386-1399.

Kreyns, P., Geng, X., \& Michael, H. A. (2020). The influence of connected heterogeneity on groundwater flow and salinity distributions in coastal volcanic aquifers. Journal of Hydrology, 586, 1-10. doi: 10.1016/j.jhydrol.2020.124863

Kunasz, I. A. (1980). Lithium in brines. Fifth Symposium on Salt, 1, 115-117.

Langevin, C., \& Guo, W. (2006). Modflow / mt3dms âĂŞ based simulation of variabledensity ground water flow and transport. Ground Water, 44(3), 339-351.

Liu, Y., Mao, X., Chen, J., \& A, B. D. (2014). Influence of a coarse interlayer on seawater intrusion and contaminant migration in coastal aquifers. Hydrological Processes, 28, 5162-5175.

Lowenstein, T. K., Hein, M. C., Bobst, A. L., Jordan, T. E., Ku, T. L., \& Luo, S. $\quad$ (2003). An assessment of stratigraphic completeness in climate-sensitive closed-basin lake sediments: Salar de atacama, chile. Journal of Sedimentary Research, 73(1), 91-104.

Mahmoodzadeh, D., \& Karamouz, M. (2019). Seawater intrusion in heterogeneous coastal aquifers under flooding events. Journal of Hydrology, 568, 1118-1130. doi: 10.1016/ j.jhydrol.2018.11.012

Marazuela, M., Vázquez-Suñé, E., Custodio, E., Palma, T., Garcia-Gil, A., \& Ayora, C. (2018). Projections to the superior colliculus from inferior parietal, ventral premotor, and ventrolateral prefrontal areas involved in controlling goal-directed hand actions in the macaque. Journal of Hydrology, 561, 223-235.

Maxey, G. B. (1968). Hydrogeology of desert basins. Groundwater, 6(5), 10-22.

Meng, G., Han, Y., Wang, S., \& Wang, Z. (2002). Seawater intrusion types and regional divisions in the southern coast of laizhou bay. Chinese Journal of Oceanology and Limnology, 20(3), 277-284.

Michael, H. A., \& Khan, M. R. (2016). Impacts of physical and chemical aquifer heterogeneity on basin-scale solute transport: Vulnerability of deep groundwater to arsenic 
contamination in bangladesh. Advances in Water Resources, 98, 147-158.

Michael, H. A., Scott, K. C., Koneshloo, M., Yu, X., Khan, M. R., \& Li, K. (2016). Geologic influence on groundwater salinity drives large seawater circulation through the continental shelf. Geophysical Research Letters, 43(10), 782-791.

Montgomery, E. L., Rosko, M. J., Castro, S. O., Keller, B. R., \& Bevacqua, P. S. (2003). Interbasin underflow between closed altiplano basins in chile. Groundwater, 41(4), 523531.

Morgan, L., Werner, A., \& Simmons, C. (2012). On the interpretation of coastal aquifer water level trends and water balances: A precautionary note. Journal of Hydrology, 280288.

Mpodozis, C., Arriagada, C., Basso, M., Roperch, C., \& Reich, M. (2005). Late mesozoic to paleogene stratigraphy of the salar de atacama basin, antofagasta, northern chile: Implications for the tectonic evolution of the central andes. Tectonophysics, 399, 125-154.

Munk, L. A., Boutt, D. F., Hynek, S. A., \& Moran, B. ～(2018). Hydrochemical fluxes and processes contributing contributing to the formation of lithium-enriched brines in a hyper-arid continental basin. Chemical Geology, 493, 37-57. doi: 10.1016/j.chemgeo.2018.05.013

Munk, L. A., Hynek, S. A., Bradley, D. A., Boutt, D. F., Labay, K., \& Jochens, H. (2016). Lithium brines: A global perspective. Review in Economic Geology, 18, 339-365.

Ortiz, C., Aravena, R., Briones, E., Suárez, R., Tore, C., \& Muñoz, J. F. (2014). Sources of surface water for the soncor ecosystem, salar de atacama basin, northern chile. Hydrological Sciences Journal, 59(2), 336-350.

Philip, J. R., \& van Duijn, C. J. (1996). Slumping of brine mounds: bounds on behaviour. Journal of Hydrology, 179, 159-180.

Placzek, C., Quade, J., Betancourt, J. L., Patchett, P. J., Rech, J. A., Latorre, C., .. English, N. B. (2009). Climate in the dry central andes over geologic, millenial, and interannual timescale. Ann. Missouri Bot. Gard., 96(3), 386-397.

Post, V., Galvis, S. C., Sinclair, P. J., \& Werner, A. D. (2019). Evaluation of management scenarios for potable water supply using script-based numerical groundwater models of a freshwater lens. Journal of Hydrology.

Post, V., Houben, J. G., \& van Engelen, J. (2018). What is the ghijben-herzberg principle and who formulated it? Hydrogeology Journal, 26(6), 1801-1807.

Post, V., Kooi, H., \& Simmons, C. (2007). Using hydraulic head measurements in variabledensity ground water flow analyses. Ground Water, 45(6), 664-671.

Qureshi, A. S. (2011). Water management in the indus basin in pakistan: Challenges and opportunities. Mountain Research and Development, 31, 3 .

Reutter, K. J., Charrier, R., Götze, H. J., Schurr, B., Wigger, P., Scheuber, E., .. B BelmontePool, A. (2006). The salar de atacama basin: a subsiding block within the western edge of the altiplano-puna plateau. Andes: Active Subduction Orogeny, 303-325.

Rissman, C., Leybourne, M., Benn, C., \& Christenson, B. (2015). The origin of solutes within the groundwaters of a high andean aquifer. Chemical Geology, 396, 164-181.

Rosen, M. (1994). The importance of groundwater in playas: A review of playa classifications and the sedimentology and hydrology of playas. Geological Society of America Special Papers, 289.

Russoniello, C. J., Fernandez, C., Bratton, J. F., Banaszak, J. F., Krantz, D. E., Andres, A. S., ... Michael, H. A. (2013). Geologic effects on groundwater salinity and discharge into an estuary. Journal of Hydrology, 498, 1-12.

Sanford, W. E., \& Pope, J. P. (2010). Current challenges using models to forecast seawater intrusion: lessons from the eastern shore of virginia, usa. Hydrogeology Journal, 18(1), 73-93.

Sawyer, A., Lazareva, O., Kroeger, K. D., Crespo, K., Chan, C. S., Stieglitz, T., \& Michael, H. (2014). Stratigraphic controls on fluid and solute fluxes across the sedimentwater interface of an estuary. Limnology and Oceanography, 59, 997-1010. doi: 10.4319/lo.2014.59.3.0997 
Scanlon, B. R., Keese, K. E., Flint, A. L., Flint, L. E., Gaye, C. B., Edmunds, W. M., \& Simmers, I. (2006). Global synthesis of groundwater recharge in semiarid and arid regions. Hydrological Processes, 20, 3335-3370.

Schaller, M. F., \& Fan, Y. (2009). River basins as groundwater exporters and importers: Implications for water cycle and climate modeling. Journal of Geophysical Research, 114, 1-20.

Schincariol, A., Schwartz, F., \& Mendoza, C. (1997). Instabilities in variable density flows : Stability and sensitivity analyses for homogeneous and heterogeneous media. Water Resources Research, 33, 31-41. doi: 10.1029/96WR02587

Stein, V., Yechieli, Y., Shalev, E., Kasher, R., \& Sivan, O. ～(2019). The effect of pumping saline groundwater for desalination on the freshâĂŞsaline water interface dynamics. Water Research, 157, 46-57.

Tejeda, I., Cienfuegos, R., Muñoz, J. F., \& Durán, M. (2003). Numerical modeling of saline intrusion in salar de atacama. Journal of Hydrologic Engineering, 8(1), 25-34.

Trabelsi, F., Ben Mammou, A., Tarhouni, J., Piga, C., \& Ranieri, G. (2013). Delineation of saltwater intrusion zones using the time domain electromagnetic method: The nabeulhammamet coastal aquifer case study. Hydrological Processes, 27, 2004-2020.

Tyler, S. W., Muñoz, J. F., \& Wood, W. W. (2006). The response of playa and sabkha hydraulics and mineralogy to climate forcing. Groundwater, 44(3), 329-338.

Vásquez, C., Ortiz, P., Suárez, F., \& Muñoz, J. (2013). Modeling flow and reactive transport to explain mineral zoning in the atacama salt flat aquifer, chile. Journal of Hydrology, 490, 114-125.

Wang, J., Song, C., Reager, J., Yao, F., Famigletti, J., Y, S., . . Wada, Y. (2018). Recent global decline in endorheic basin water storages. Nature Geoscience, 11, 926-932.

Werner, A. D., Bakker, M., Post, V. E. A., Vandenbohede, A., Lu, C., Ataie-Ashtiani, B., .. . Barry, D. A. (2013). Seawater intrusion processes, investigation and management: Recent advances and future challenges. Advances in Water Resources, 51, 3-26. doi: 10.1016/j.advwatres.2012.03.004

Werner, A. D., \& Simmons, C. T. (2009). Impact of sea-level rise on sea water intrusion in coastal aquifers. Groundwater, 47(2), 197-204.

Wooding, R. A., Tyler, S. W., \& White, I. (1997). Convection in groundwater below an evaporating salt lake : 1 . onset of instability. Water Resources Research, 33(6), 11991217.

Yager, R., McCoy, K., Voss, C., E, S. W., \& Winston, R. B. (2017). The role of uplift and erosion in the persistence of saline groundwater in the shallow subsurface. Geophysical Research Letters, 98, 147-158.

Ye, M., Wang, L., Pohlmann, K. F., \& Chapman, J. B. (2016). Evaluating groundwater interbasin flow using multiple models and multiple types of data. Ground Water, 54(6), 113.

Yechieli, Y. (2000). Fresh-saline ground water interface in the western dead sea area. Groundwater, 38(4), 615-623.

Yechieli, Y., Kafri, U., Goldman, M., \& I, V. C. (2001). Factors controlling the configuration of the fresh-saline water interface in the dead sea coastal aquifers: Synthesis of tdem surveys and numerical groundwater modeling. Hydrogeology Journal, 9(4), 367-377.

Yechieli, Y., Shalev, E., Kiro, Y., \& Kafri, U. (2010). Response of the mediterranean and dead sea coastal aquifers to sea level variations. Water Resources Research, 46.

Yechieli, Y., \& Wood, W. (2002). Hydrogeologic processes in saline systems: Playas, sabkhas, and saline lakes. Earth Science Reviews, 58, 343-365. doi: 10.1016/ S0012-8252(02)00067-3

Zhu, C., Waddell, R. K., Star, I., \& Ostrander, M. (1998). Responses of ground water in the black mesa basin, northeastern arizona, to paleoclimatic changes during the late pleistocene and holocene. Geology, 26(2), 127-130. 